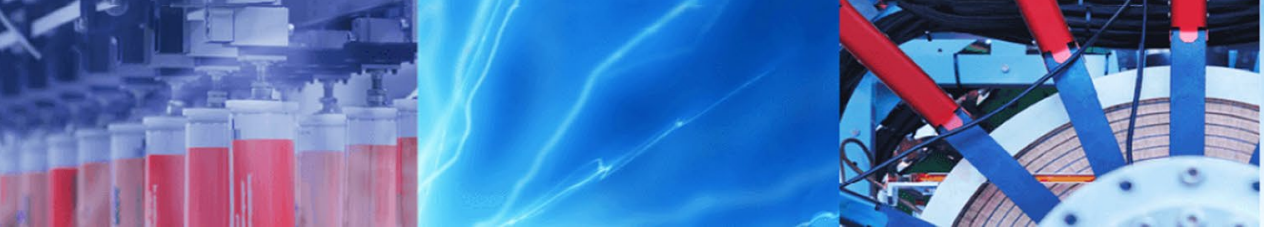

Research Article

\title{
Experimental and numerical behavior of hybrid-fiber-reinforced concrete compression members under concentric loading
}

\author{
Ali Raza ${ }^{1}$ (D) Q Qaiser uz Zaman Khan ${ }^{1}$
}

Received: 15 October 2019 / Accepted: 10 March 2020 / Published online: 18 March 2020

(c) Springer Nature Switzerland AG 2020

\begin{abstract}
The modern research is aimed to enhance the tensile properties of concrete so that its performance should be made better in various reinforced concrete structures. In the current study, twenty hybrid-fiber-reinforced concrete (HFRC) columns and one plain concrete column were cast to examine the effect of hybrid fibers on the axial capacity, load-deflection response and cracking patterns of columns under axial concentric loading. All specimens were square in cross section having a side length of $150 \mathrm{~mm}$ and a height of $1200 \mathrm{~mm}$. Two different types of fibers were used; one is steel fibers (SF) and second is polypropylene fibers (PPF). Four different volumetric ratios of SF $(0.7 \%, 0.8 \%, 0.9 \%, 1.0 \%)$ and five different ratios of PPF $(0.1 \%, 0.3 \%, 0.5 \%, 0.7 \%, 0.9 \%)$ were used in the current study. The results indicate that the combination of $0.8 \% \mathrm{SF}$ and $0.5 \%$ PPF performed well for load-carrying capacity and a combination of $0.9 \%$ SF and $0.3 \%$ PPF presented the best performance for the ductility of HFRC columns. Moreover, a constitutive finite element model (FEM) was proposed using concrete damaged plastic (CDP) model in ABAQUS for predicting the axial behavior and crack patterns of HFRC columns under concentric loading. A close agreement was observed between the experimental measurements and FE predictions. Finally, a detailed comparison of theoretical axial capacities of HFRC columns was performed using the predictions of various codes and proposed equations.
\end{abstract}

Keywords Finite element analysis (FEA) - Axial capacity · Steel fibers · Polypropylene fibers · Damaged plasticity model · Hybrid fibers

\section{Introduction}

The brittleness of concrete with its increased strength is the main concern of concrete. Therefore, increasing the strength of concrete leads to lower ductility which is a serious drawback of using concrete in construction works. The plain concrete is a highly brittle material with inadequate flexural strength and tensile strength, low energy absorption and low toughness [1, 2]. This drawback between strength and ductility of concrete can be compensated by incorporating short fibers [3]. Thus, there is a need to improve the properties of concrete to enhance the seismic behavior of different structural components which can be achieved by adding different types of fibers in plain concrete [4]. However, the fibers can bridge the loads throughout the cracks and increase the toughness and limit the crack propagation in concrete [5]. The hybrid-fiber-reinforced concrete (HFRC) using a combination of different fibers such as the steel fibers with high elastic modulus and the polymetric fibers with low elastic modulus is primarily developed to attain a desirable balance between

Electronic supplementary material The online version of this article (https://doi.org/10.1007/s42452-020-2461-5) contains supplementary material, which is available to authorized users.

Ali Raza, araza4846@gmail.com; $₫$ Qaiser uz Zaman Khan, dr.qaiser@uettaxila.edu.pk| ${ }^{1}$ Department of Civil Engineering, University of Engineering and Technology, Taxila 47080, Pakistan. 
the strength and ductility of the material against blast and impact loading [6].

It can be observed from the previous experimental studies of steel and metallic fibers [7-14], natural fibers [15] and polymetric fibers [16-18] that the incorporation of single type of fibers in concrete does not significantly influence the various characteristics of concrete except strain and crack resistance, while the incorporation of hybrid fibers effectively increase the resistance to cracking and strain efficiency in several levels $[19,20]$. To improve the ductility, bridge the cracks and prevent their propagation in the concrete, the addition of fibers is an effective way [21]. Some hybrid fibers cementitious composites can improve the performance of concrete structures under different cyclic, seismic, static and impact loadings and can be used for the retrofitting of different masonry and concrete structures [22-24]. The fibers in concrete with low-volume fractions acts as the secondary reinforcement against cracking. Though fibers do not significantly increase the compressive strength of concrete, they improve the flexural and tensile strength of concrete [25-29].

Although many researchers investigated the performance of HFRC through analytical modeling [30-33] which played a significant role in investigating the behavior of HFRC, but these researches could not fully explore the fundamental mechanism and performance under different loading conditions. Therefore, to overcome this deficiency of analytical modeling one can move toward the three-dimensional finite element modeling (FEM) which saves cost and time in comparison with experimental work and can investigate the complex damaging mechanisms of the concrete [34]. The finite element model should follow the assumptions and boundary conditions made in experiments but also it should be simple with balanced mesh size, element types and complexity to accurately predict the behavior of structural members in minimum time. Thus, we can say that numerical modeling is an efficient tool for the analysis and design of structures in the engineering research area if we have strong background knowledge of finite element modeling [35]. Chowdhury et al. [36] performed the experimental investigation and finite element analysis (FEA) of brick and stone-made concrete reinforced with steel fibers (SF) and concluded that by the addition of volumetric ratio of $1.5 \%$ SF fibers, the tensile and compressive performance of concrete increased up to $146 \%$ and $17 \%$, respectively. Moreover, they also found a good correlation among the experimental and FEA predictions.

It was observed from previous studies that no numerical model was proposed for predicting the axial behavior of HFRC columns. The aim of the present research is to experimentally and numerically collaborate the structural
Table 1 Characteristics of cement used in the present research

\begin{tabular}{lll}
\hline S. No & Description & Results \\
\hline & Specific gravity & 3.030 \\
& Initial setting time & $91 \mathrm{~min}$ \\
& Final setting time & $225 \mathrm{~min}$ \\
& Consistency & $28.75 \%$ \\
Compressive strength at 28 days & $42 \mathrm{MPa}$ \\
& Fineness of cement & $319 \mathrm{~m}^{2} / \mathrm{kg}$ \\
\hline
\end{tabular}

Table 2 Specifications of coarse and fine aggregates

\begin{tabular}{lllc}
\hline S. No & Description & Fine aggregates & $\begin{array}{l}\text { Coarse } \\
\text { aggre- } \\
\text { gates }\end{array}$ \\
\hline 1 & Specific gravity (SG) & 2.67 & 2.71 \\
2 & Fineness modulus & 2.41 & - \\
3 & Water absorption & $1.21 \%$ & $0.82 \%$ \\
\hline
\end{tabular}

performance of hybrid-fiber-reinforced concrete (HFRC) square compression members under axial concentric loadings. A total of 21 square columns were cast with different low-volumetric ratios of SF and polypropylene fibers (PPF) to examine their effect on the cracking and load-carrying behavior under axial loading. Furthermore, a nonlinear FEA model was simulated and calibrated using the experimental outputs. A good relationship between the results of the FEA model and experimental work was observed. Predictions of axial strength of HFRC columns were also performed using various international standards. The outputs of this research are helpful for the structural designers while designing the concrete columns with hybrid fibers. Moreover, the FEM saves the time and cost of testing and casting the specimens.

\section{Experimental program}

Ordinary Portland Cement (Type-Il, Grade 43) confirming the specifications of ASTM C150/150M-18 [37] was used in the present research for the fabrication of HFRC specimens. Some of the characteristics of the cement are given in Table 1.

Coarse aggregates were selected as per ASTM C33-18 [38] specifications. The selected aggregate specification number was 67 where the maximum passing size of aggregate was taken as $19 \mathrm{~mm}$ keeping in view the maximum designed cover for columns was $20 \mathrm{~mm}$ so that the concrete may pass through cover easily and furthermore to avoid honeycombing. The specifications of coarse and fine aggregates are given in Table 2. 
Table 3 Specifications of steel and polypropylene fibers

\begin{tabular}{lll}
\hline Property & $\begin{array}{l}\text { Description/value } \\
\text { for SF }\end{array}$ & $\begin{array}{l}\text { Description/value } \\
\text { for PPF }\end{array}$ \\
\hline Length & $25 \pm 1 \mathrm{~mm}$ & $14 \mathrm{~mm}$ \\
Aspect ratio (L/D) & $>45(52)$ & - \\
Diameter & $0.55 \pm 0.05 \mathrm{~mm}$ & $22 \mu \mathrm{m}$ \\
Ultimate strength & $>600 \mathrm{MPa}$ & $400 \mathrm{MPa}$ \\
Specific gravity & 7.82 & 0.91 \\
Melting point & $2530{ }^{\circ} \mathrm{C}$ & $1700{ }^{\circ} \mathrm{C}$ \\
Young's modulus & $20\left(\mathrm{kN} / \mathrm{mm}^{2}\right)$ & $0.45\left(\mathrm{kN} / \mathrm{mm}^{2}\right)$ \\
Elongation at failure & $3.5 \%$ & $15 \%$ \\
\hline
\end{tabular}

Hooked ended steel fibers (SF) were used as a reinforcement in addition to monofilament polypropylene fibers (PPF) with the specifications as presented in Table 3 and shown in Fig. 1.

Superplasticizer increases the fluidity in order to allow the flow of fluid under gravity for the achievement of the required degree of consolidation in concrete [39]. Chemrite NN, as a superplasticizer, was used with the specifications (Table 4) fulfilling the specifications of ASTM C494 / C494M-17 [40].

The quantities of various constituents of concrete used in the present work are given in Table 5.

\subsection{Specimens design}

The extensive ratios of fibers were included in the test program, because the literature represented that the peak strength shall lie within this range since the hybrid concrete is not a common area of research; hence the data in the field are fewer and that leads to a wide range of samples, and another purpose for such a large number of
Table 4 Specifications of superplasticizer

\begin{tabular}{lll}
\hline S. No & Description & Details \\
\hline 1 & Density of at $25^{\circ} \mathrm{C}$ & Approximately $1.18 \mathrm{~kg} / \mathrm{l}$ \\
2 & pH value & 8.00 \\
4 & Toxicity & Non-toxic \\
5 & Transportation & Non-hazardous \\
\hline
\end{tabular}

Table 5 Quantities of concrete constituents

\begin{tabular}{ll}
\hline Material quantity & Unit weight $\left(\mathrm{Kg} / \mathrm{m}^{3}\right)$ \\
\hline Cement & 468.26 \\
Coarse Aggregates & 1310.86 \\
Fine aggregates & 655.43 \\
Superplasticizer & $0.5 \%$ by volume \\
Water & 220.08 \\
Steel fibers (SF) & $0.7-1.0 \%$ by volume \\
Polypropylene fibers (PPF) & $0.1-0.9 \%$ by volume \\
\hline
\end{tabular}

specimen was to bind up the research in hybrid concrete columns using steel fibers and polypropylene fibers providing the baseline for design of hybrid concrete columns. The test program was an extensive program setup including twenty different mix ratios of hybrid-fiber-reinforced concrete all along with a control specimen of reinforced cement concrete which had no fibers. The cross-sectional details are depicted in Fig. 2. The cross section of the specimen was scaled-down for a two-story model building having conventional live loads supporting $10 \mathrm{~m}$ on both sides, and hence the column was considered of about $4 \mathrm{~m}$ high. The said column was axially loaded and a short column hence the steel and other cross-sectional details also scaled-down except the shear reinforcement which
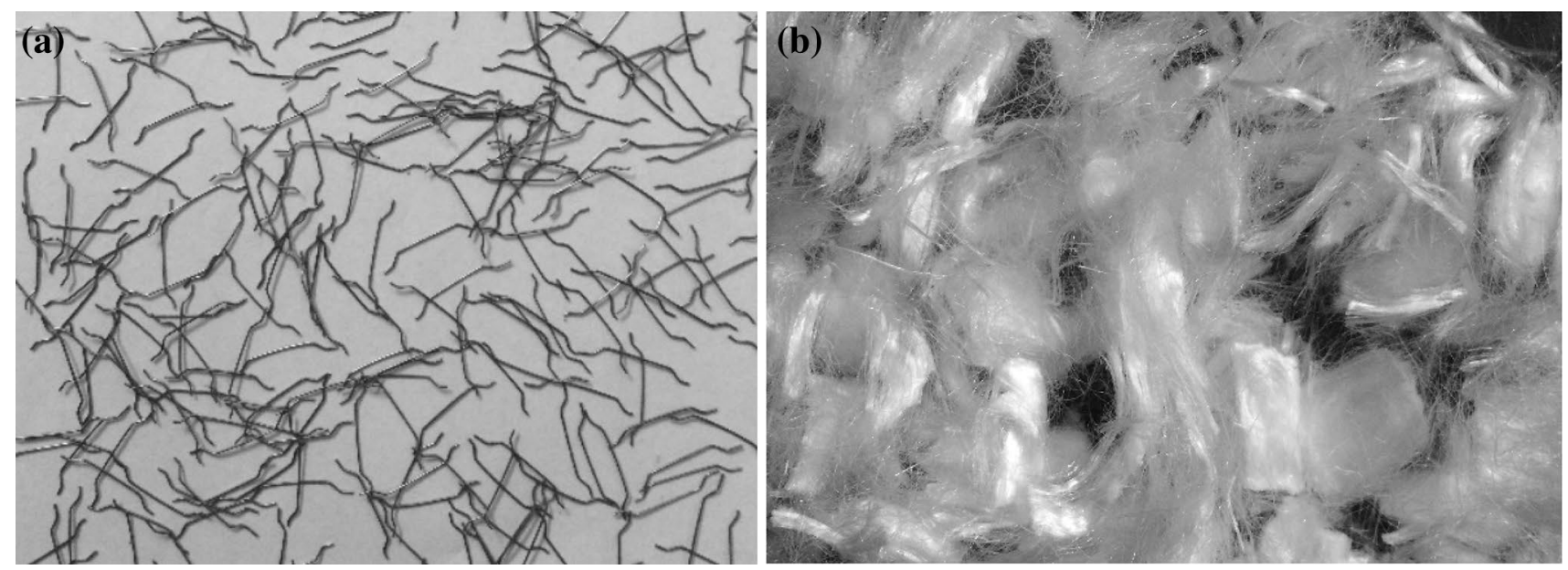

Fig. 1 a Steel fibers and $\mathbf{b}$ polypropylene fibers 
Fig. 2 Cross-sectional details of specimens

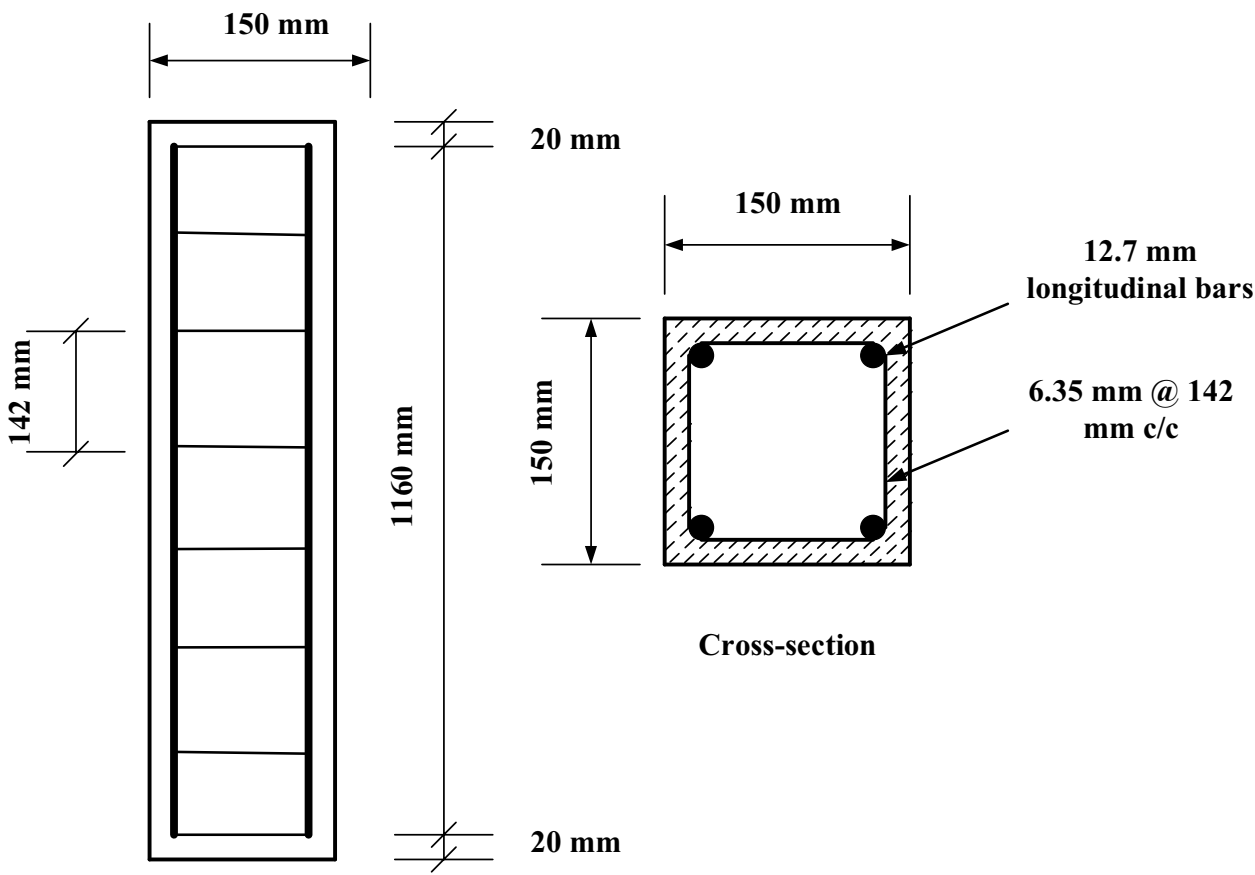

Longitudinal section

was subject to $\mathrm{ACl}$ 318-08 [41] minimum requirements. The cross section was squared to $150 \mathrm{~mm}$ side length. The length of the column was maintained at $1200 \mathrm{~mm}$ because of the available maximum gauge length in $5000 \mathrm{kN}$ capacity compression testing machines at the Department of Civil Engineering, University of Engineering and Technology, Taxila, Pakistan. While the cover was maintained at $20 \mathrm{~mm}$ minimum as the maximum size of aggregate under consideration was $19 \mathrm{~mm}$ so this was decided to provide the minimum cover of $20 \mathrm{~mm}$ violating the scaled-down requirement of maximum $10 \mathrm{~mm}$. The longitudinal steel was kept uniform throughout the length of columns by providing four $12.7 \mathrm{~mm}$ diameter bars having a yield strength of $418 \mathrm{MPa}$. The transverse reinforcement was provided to HFRC columns using $6.35 \mathrm{~mm}$ diameter steel stirrups at $142 \mathrm{~mm} \mathrm{c/c} \mathrm{spacing} \mathrm{as} \mathrm{presented} \mathrm{in} \mathrm{Fig.} \mathrm{2.} \mathrm{The}$ specifications of the mix design and compressive strengths of mixes are presented in Table 6.

\subsection{Testing procedure of specimens}

The specimens were brought to the platform of compression testing machine after 28 days of casting including 7 -day normal water curing. The experimental program was so devised that the columns compression testing machine would stay for five seconds at every stress interval which was maintained at $0.2-0.26 \mathrm{MPa}$ corresponding to a load of 5-6 KN depending upon the stress release in the material. The relevant axial strains were continuously measured with load application at specific intervals. Meanwhile, the vertical deflections with strain gauges were also measured at intervals of every $50 \mathrm{KN}$ load and were noted manually to find out the coherence between the material strain and load-deflection strain. The testing arrangement of the HFRC column is shown in Fig. 3.

\section{Finite element modeling}

\subsection{Concrete and steel behavior}

A general-purpose program ABAQUS was used for the finite element (FE) simulations of HFRC columns. The bottom end of the specimens was restrained in all directions for displacement and rotation, and the top end was kept free. The contact/bond between reinforcement and concrete was defined by using embedded region constraint available in ABAQUS which perfectly connects the degrees of freedoms (DOF) of truss elements to the 8-noded brick elements of concrete. The steel plates were connected to the top and bottom of the column using tie constant for the application of uniformly distributed load on the top and boundary conditions on the bottom. The numerical simulations of the behavior of reinforced concrete (RC) under multi-axial loading is a challenging task. Three models are there for the numerical simulations of RC: concrete damaged plastic (CDP), smeared crack and brittle crack models. One can accurately predict the behavior of RC 
Table 6 Test matrix of the present research

\begin{tabular}{llllll}
\hline Mix ratio name & Sample label & SF (\%) & PPF (\%) & $\begin{array}{l}\text { Total volume of } \\
\text { fibers (\%) }\end{array}$ & $\begin{array}{l}\text { Compressive } \\
\text { strength (MPa) }\end{array}$ \\
\hline M1 & HC0.0-0.0 & 0.0 & 0.0 & 0.0 & 30.05 \\
M2 & HC0.7-0.1 & 0.7 & 0.1 & 0.8 & 34.38 \\
M3 & HC0.7-0.3 & 0.7 & 0.3 & 1.0 & 34.92 \\
M4 & HC0.7-0.5 & 0.7 & 0.5 & 1.2 & 33.69 \\
M5 & HC0.7-0.7 & 0.7 & 0.7 & 1.4 & 33.30 \\
M6 & HC0.7-0.9 & 0.7 & 0.9 & 1.6 & 32.34 \\
M7 & HC0.8-0.1 & 0.8 & 0.1 & 0.9 & 32.89 \\
M8 & HC0.8-0.3 & 0.8 & 0.3 & 1.1 & 37.81 \\
M9 & HC0.8-0.5 & 0.8 & 0.5 & 1.3 & 32.73 \\
M10 & HC0.8-0.7 & 0.8 & 0.7 & 1.5 & 32.05 \\
M11 & HC0.8-0.9 & 0.8 & 0.9 & 1.7 & 31.04 \\
M12 & HC0.9-0.1 & 0.9 & 0.1 & 1.0 & 32.76 \\
M13 & HC0.9-0.3 & 0.9 & 0.3 & 1.2 & 33.03 \\
M14 & HC0.9-0.5 & 0.9 & 0.5 & 1.4 & 33.56 \\
M15 & HC0.9-0.7 & 0.9 & 0.7 & 1.6 & 33.11 \\
M16 & HC0.9-0.9 & 0.9 & 0.9 & 1.8 & 32.33 \\
M17 & HC1.0-0.1 & 1.0 & 0.1 & 1.1 & 33.17 \\
M18 & HC1.0-0.3 & 1.0 & 0.3 & 1.3 & 35.17 \\
M19 & HC1.0-0.5 & 1.0 & 0.5 & 1.5 & 36.67 \\
M20 & HC1.0-0.7 & 1.0 & 0.7 & 1.7 & 31.57 \\
M21 & HC1.0-0.9 & 1.0 & 0.9 & 1.9 & \\
\hline
\end{tabular}
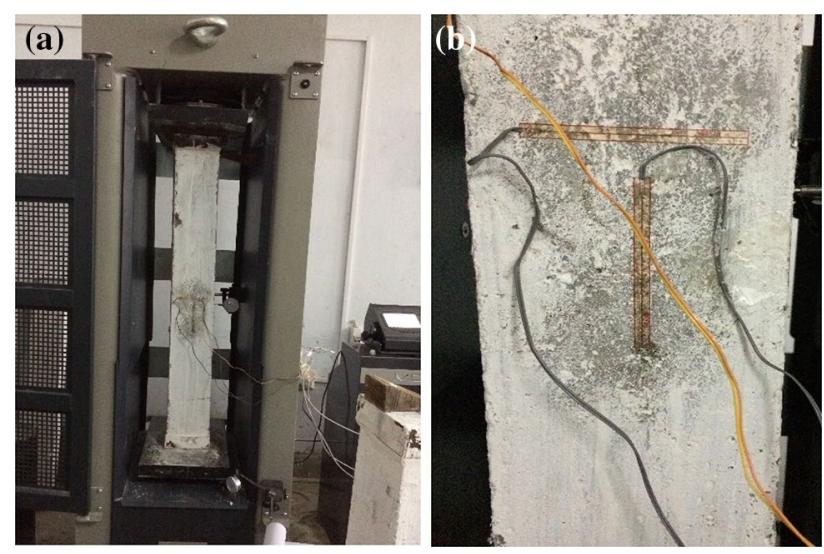

Fig. 3 a Testing of HFRC column specimens. b Strain gauges on the surface of columns

by using (CDP) model which is available in the ABAQUS standard [42-45]. This model defined the damage mechanism of concrete in two ways: one is compressive crushing under multi-axial loading and the second is tensile cracking. Both the crushing and cracking behaviors of concrete were defined in ABAQUS. In numerical simulations, the elastic behavior was defined using two parameters of concrete, i.e., elastic modulus and Poisson's ratio. The plastic behavior of concrete which is a sub-part of the CDP model was defined using various parameters of concrete obtained from the calibration. The CDP model consists of three behaviors of RC: plastic behavior with dilation angle, viscosity and shape factor parameters, loading eccentricity and stresses ratio; compressive behavior with concrete compressive and tensile damage parameters and tensile behavior with yielding stress and tensile strains. The CDP model for plain concrete structures [46] is presented in Fig. 4a. According to the stress-strain model (Fig. 4b) proposed by Eurocode 2 [47], the linear elastic behavior of concrete can be taken up to $40 \%$ of its compressive strength $(\mathrm{fc})$. For the simulations of plastic behavior, all the plastic parameters were calibrated for different values as discussed in the calibration section. For the simulations of compressive behavior of concrete, the stresses were calculated using the empirical equation proposed by [48] as represented by Eq. (1)

$\sigma_{c}=\frac{E_{o} \varepsilon}{1+\left(\frac{\varepsilon}{\varepsilon_{c o}}\right)^{2}}$

Similarly, the strains model (Eqs. 2 and 3) proposed by Majewski [49] were used in the present research for the predictions of strains of RC. The tension and compression damage parameters of concrete in the CDP model were defined using Eqs. (4) and (5). The stress-strain curves of HFRC with different quantities of hybrid fibers 

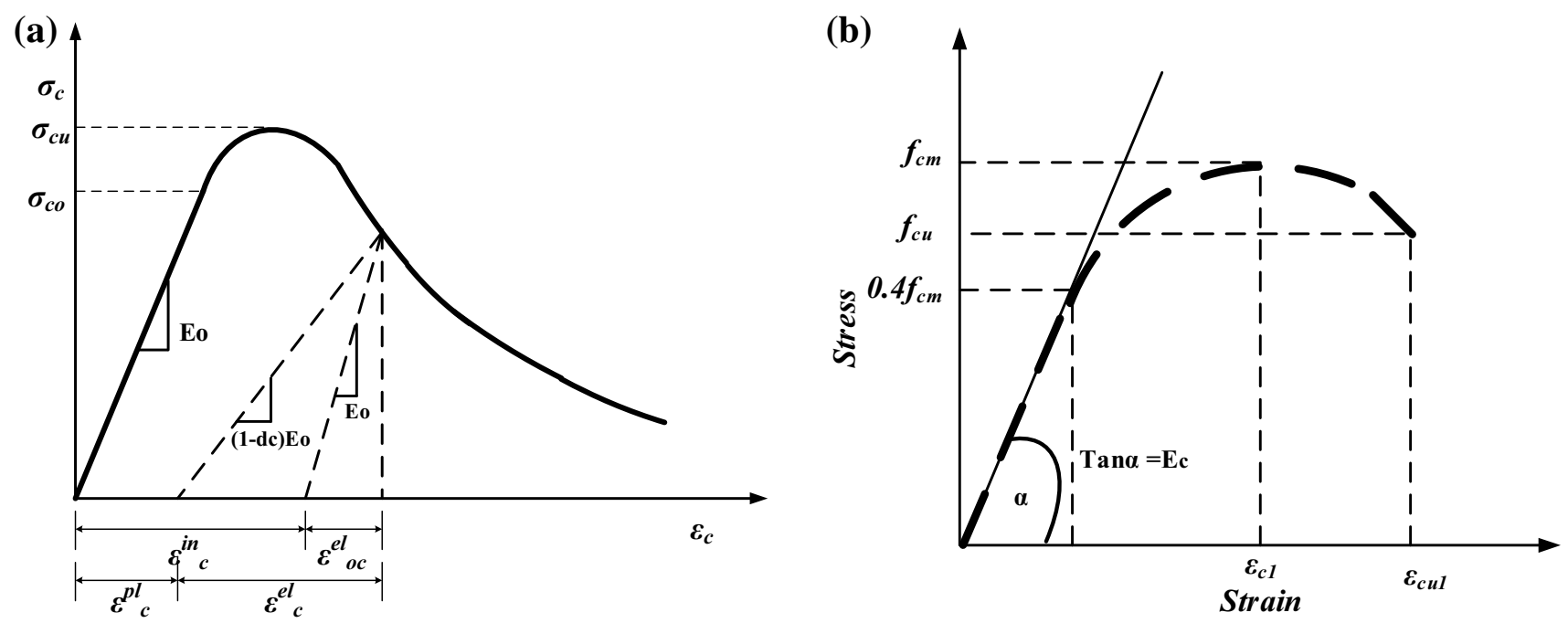

Fig. 4 a Plain concrete CDP model [46], b stress-strain model [47]

were constructed using the experimental compressive strength values of the mixes provided in Table 6 .

$\varepsilon_{c, 1}=0.0014\left[2-\mathrm{e}^{-0.024 f_{c m}}-\mathrm{e}^{-0.140 f_{c m}}\right]$

$\varepsilon_{c u, 1}=0.004-0.0011\left[1-\mathrm{e}^{-0.0215 f_{c m}}\right]$

$d_{c}=\frac{\left(1-\eta_{c}\right) \varepsilon_{c}^{\text {in }} E_{o}}{\sigma_{c}+\left(1-\eta_{c}\right) \varepsilon_{c}^{\text {in }} E_{o}}$

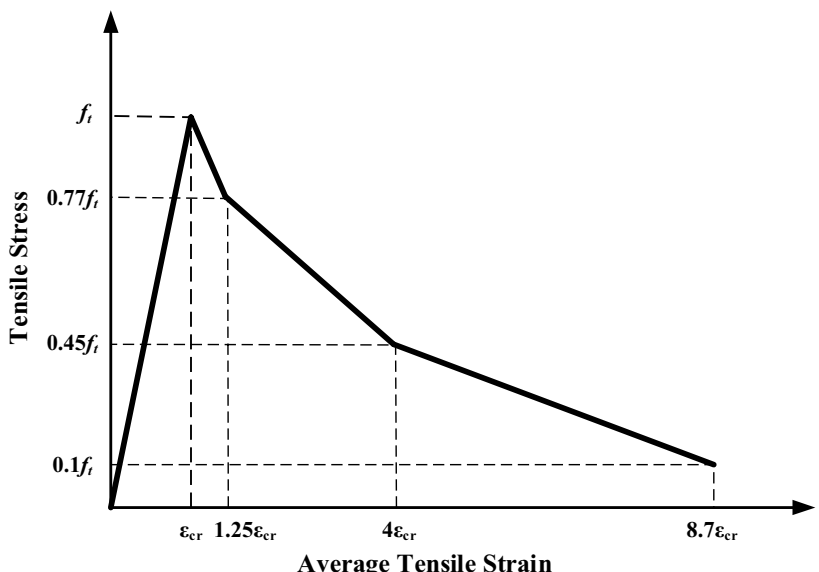

$d_{\mathrm{t}}=\frac{\left(1-\eta_{t}\right) \varepsilon_{t}^{\mathrm{in}} E_{o}}{\sigma_{\mathrm{t}}+\left(1-\eta_{\mathrm{t}}\right) \varepsilon_{t}^{\mathrm{in}} E_{\mathrm{o}}}$

where $\varepsilon_{c}^{\text {in }}$ and $\varepsilon_{t}^{\text {in }}$ are the strains in the inelastic region of concrete in compression and tension, respectively, and $\eta_{c}$ and $\eta_{\mathrm{t}}$ are some portions of concrete strain in tension and compression that can be taken as 0.6 and 0.4 , respectively. $E_{\mathrm{o}}$ is the elastic modulus of concrete and $\sigma_{c}$ and $\sigma_{\mathrm{t}}$ are the uniaxial compressive and tensile stresses of concrete. For the simulations of the tensile performance of HFRC, the tension stiffening model [50] was used as presented in Fig. 5. The numeric values of the ultimate tensile strengths of HFRC mixes were determined using Eq. (6) [51].

$f_{\mathrm{t}}^{\prime}=0.33 \sqrt{f_{\mathrm{c}}^{\prime}}(\mathrm{MPa})$

For the modeling of reinforcement, a bilinear elastoplastic material model was selected $[45,52]$ with a hardening ratio of $1 \%$ as represented in Fig. 6 . The yielding of steel bars was $418 \mathrm{MPa}$, and elastic modulus was taken as 200GPa.

\section{SN Applied Sciences}

Fig. 5 Tension stiffening model for HFRC used in the present work

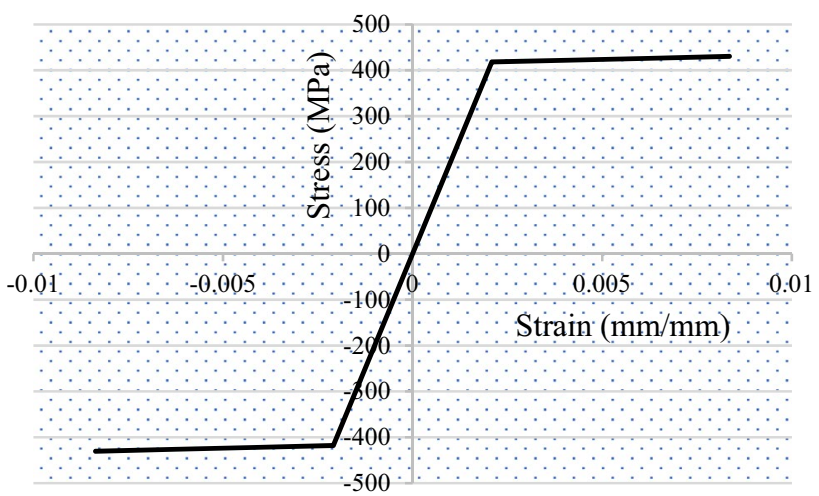

Fig. 6 Bilinear behavior of steel bars 


\subsection{Validation of control model}

For the numerical work, it is essential to calibrate the numerical results using the experimental results. For calibration, a specimen (HC0.7-0.1) was selected and its finite element model was constructed using ABAQUS. The geometry and boundary conditions for the FEM of columns are represented in Fig. 7. The loading was applied in the form of the displacement control technique. A concentric load of $20 \mathrm{~mm}$ was implemented at the top center of the HFRC column specimens to investigate the axial behavior of HFRC columns.

The sensitivity analysis of the load-deflection curve of control specimen for the different values of viscosity parameter (VP), stress ratio $\left(\sigma_{\mathrm{bo}} / \sigma_{\mathrm{co}}\right)$, shape factor for yielding $(\mathrm{Kc})$, dilation angle $(\psi)$, and loading eccentricity $(\varepsilon)$ was assessed as presented in Fig. 8. The numeric values used for VP were $0.0005,0.001,0.0015,0.002$ and 0.0025 . It was observed that the percentage increase of $30 \%$ in the ultimate load of the control model was occurred by increasing the VP from 0.0005 to 0.0025 . The close agreement between experimental and FEA results was found at a value of 0.002 . The different values used for the dilation angle of $\mathrm{RC}$ were $30,34,38,42$ and $46^{\circ}$. The effect of the dilation angle was insignificant in the elastic region, but in the plastic region of the load-deflection curve, it was found to be effective. Similarly, the calibration of the control model for $\sigma_{\mathrm{bo}} / \sigma_{\mathrm{co}}$ and $\varepsilon$ was performed, and it was observed that the variation of these parameters does not affect the load-deflection behavior of HFRC columns. Thus, the default values for these parameters, i.e., 1.16 and 0.1 were taken for stress ratio and eccentricity, respectively. However, the shape factor Kc has an effect on the inelastic region of the load-deflection curve only. The best results were obtained using a value of 0.67 for the shape factor.
The effect of variation of mesh size for the concrete and steel bars elements was also examined. The used mesh sizes were from 20 to $35 \mathrm{~mm}$ with an increment of $5 \mathrm{~mm}$. The best approximation was achieved at a mesh size of $20 \mathrm{~mm}$ which can be observed from Fig. 8 .

The study of various element types for the RC and reinforcement was done for hexahedral, tetrahedral and triangular elements of concrete and two-noded and threenoded truss elements of steel bars. The C3D8R elements for concrete and T3D2R elements for steel bars gave close agreement for the load-deflection curve of the control model as presented in Fig. 9.

\section{Results and discussion}

The percentage discrepancy of the control model for the experimental and FEA results was $2.27 \%$ for ultimate load and $3.28 \%$ for deflection at ultimate loading. This discrepancy may be due to a large number of reasons such as (1) The dissimilitude in the properties of materials that were used in the concrete mixture. The actual properties of concrete such as dilation angle, damage parameters and viscosity parameter, etc., may not be the same as considered in the finite element simulations after the extensive calibration. (2) The experimental limitations including casting, fabrication and instrumentation. The fabrication of the specimens such as placing and compaction of concrete may vary for each of the specimen causing the variations in results. But in FEA, the errors due to fabrication of specimens cannot occur, because it does not consider the fabrication process of specimens. (3) The selected boundary conditions in the finite element simulations. It is a very difficult and challenging task to simulate the actual testing conditions.
Fig. 7 Finite element model showing, a geometry, b meshed elements, c embedded steel to concrete, $\mathbf{d}$ boundary conditions and loading
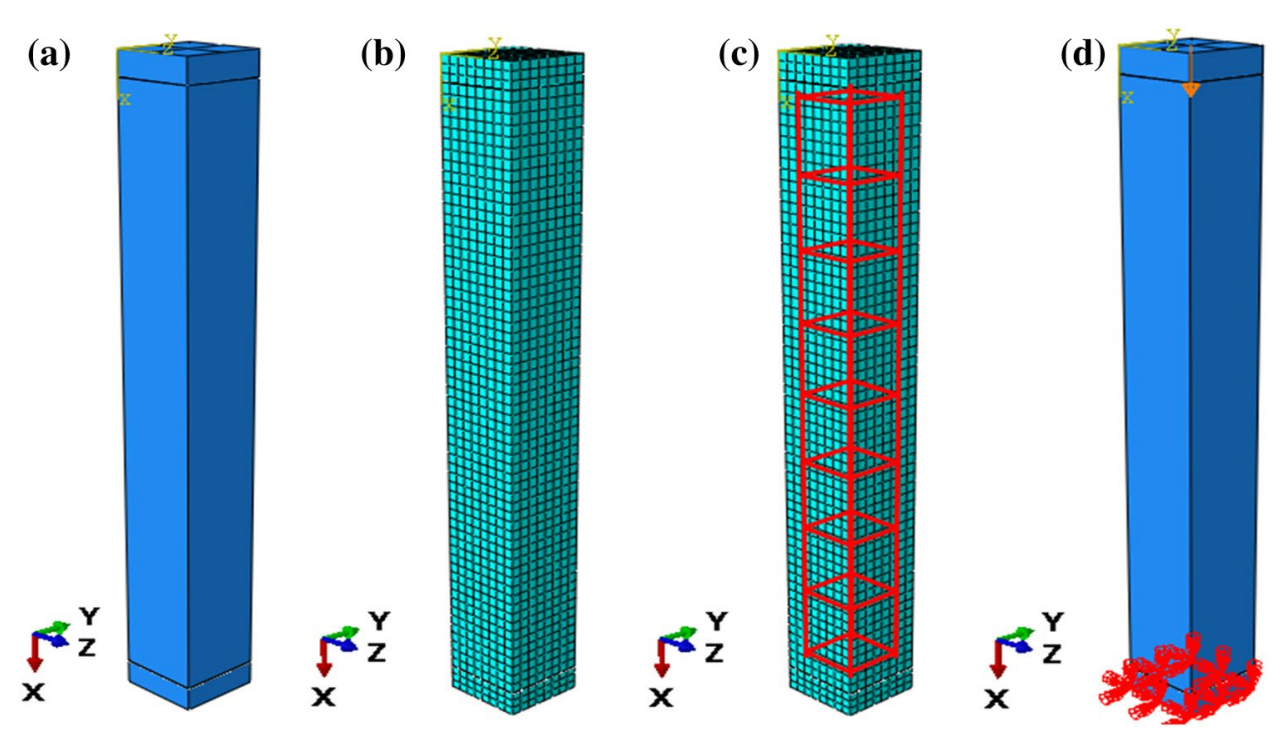

SN Applied Sciences A SPRINGER NATURE journal 

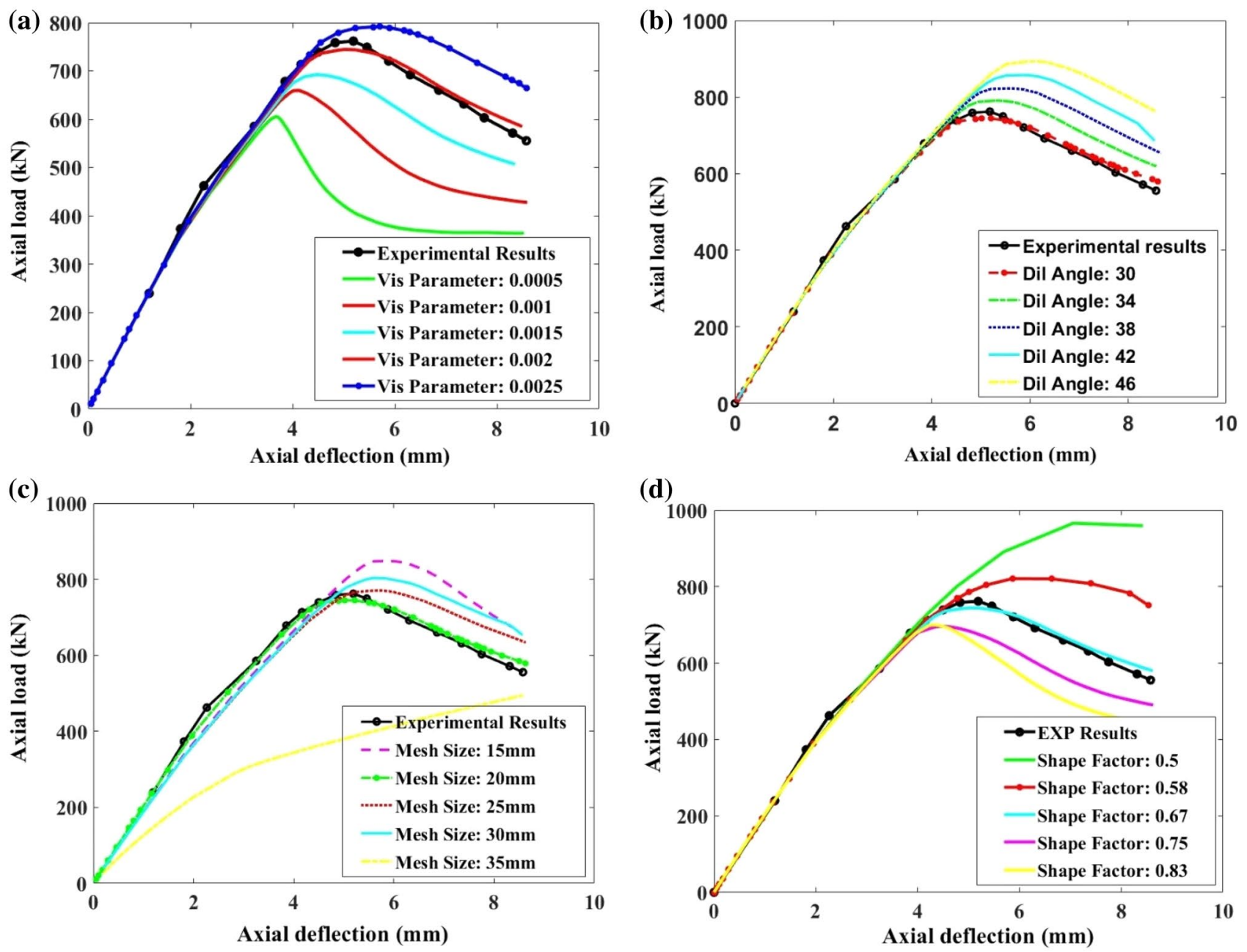

Fig. 8 Load-deflection sensitivity analysis due to variations of a viscosity parameter (VP), b dilation angle (DA), c size of elements (MS), $\mathbf{d}$ shape factor $(\mathrm{Kc})$

During FEA of compression test, the degrees of freedom (DOF) on the bottom end of the specimen was kept fixed in all directions and top end was kept free to translate and rotate in any of the direction, but in experimental tests, some of the DOF may not be zero on the bottom and the some of the DOF may be zero on the top end of the specimens causing the inconsistencies of the results.

The experimental and finite element results of all the HFRC column specimens in terms of ultimate loading capacity and axial deflection corresponding to the ultimate loads are presented in Table 7. After the selection of the control FEA model, it was used for the analysis of all remaining HFRC columns in order to obtain their numerical load-deflection curves. It can be observed from the results that the average percentage difference among the FEA and experimental outputs of all HFRC specimens was $4.72 \%$ and $12.52 \%$ for ultimate loading capacity and corresponding axial shortening, respectively.

\subsection{Cracks patterns}

Due to the brittle nature of concrete, the concrete cover was spalled out and cracks were penetrated the concrete material quite earlier for the plain concrete column as compared with the HFRC columns. This is because of the fiber matrix in the concrete stopping the peeling off concrete material into debris. The description of the crack patterns produced in each of the column specimens was mentioned as for the specimen $\mathrm{HCO} 0.0-0.0$, the concrete cover at failure site spalled with exposed reinforcement, and the failure pattern was mainly vertical cracks near one corner and diagonal crack near edge; for HC0.7-0.1, there were diagonal cracks at the center of column, horizontal cracks at one side and the diagonal cracks at another side. Similarly, for different specimens, the failure was in the form of either vertical cracks at the end or diagonal cracks at the center or end of the columns. 

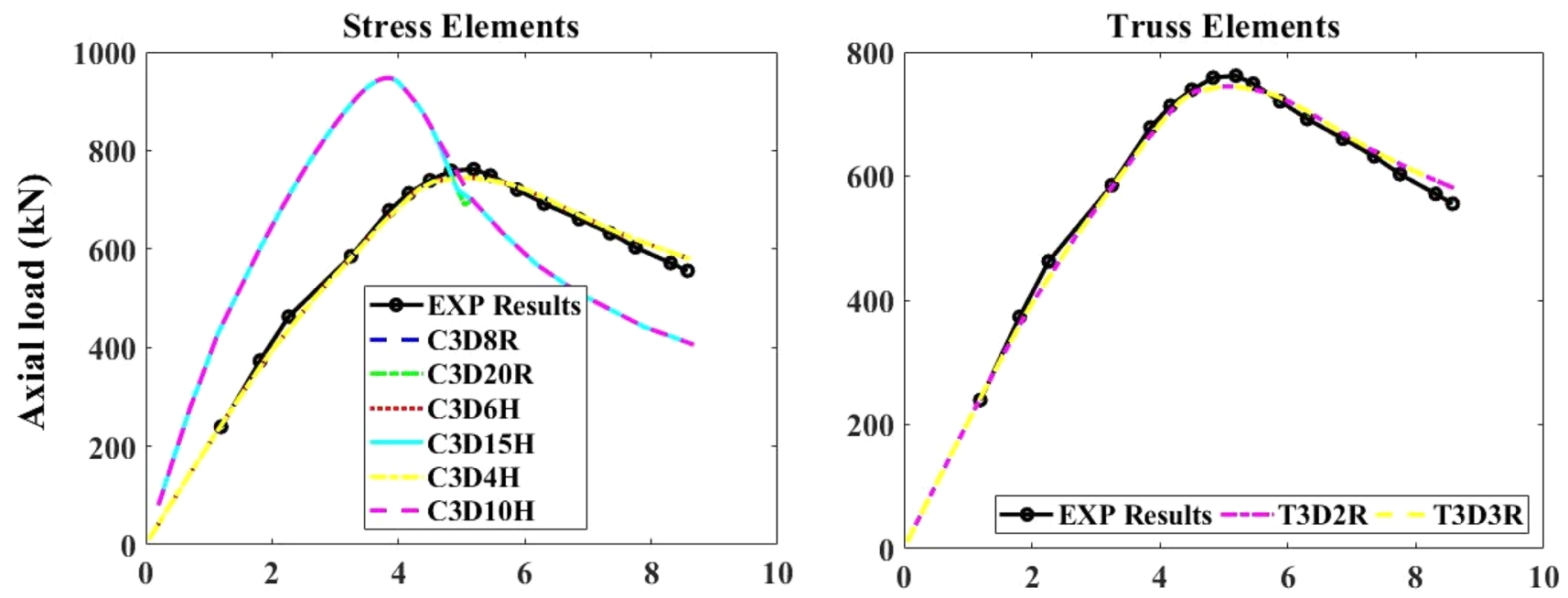

Axial deflection (mm)

Fig. 9 Load-deflection sensitivity analysis due to different elements types of concrete and reinforcement

Table 7 FEA and experimental results of ultimate crack load and corresponding deflections

\begin{tabular}{|c|c|c|c|c|c|c|c|c|}
\hline \multirow{2}{*}{$\begin{array}{l}\text { Specimen } \\
\text { label }\end{array}$} & \multicolumn{2}{|c|}{ Experimental results } & \multicolumn{2}{|l|}{ FEA results } & \multirow{2}{*}{$\begin{array}{l}\text { \%age differ- } \\
\text { ence in ulti- } \\
\text { mate loads }\end{array}$} & \multirow{2}{*}{$\begin{array}{l}\text { \%age differ- } \\
\text { ence in def. } \\
\text { at ult. loads }\end{array}$} & \multirow{2}{*}{$\begin{array}{l}\text { Avg. \%age } \\
\text { Discrepancy } \\
\text { in ult. loads }\end{array}$} & \multirow{2}{*}{$\begin{array}{l}\text { Avg. \%age } \\
\text { Discrepancy in } \\
\text { deflections at } \\
\text { ult. loads }\end{array}$} \\
\hline & $\begin{array}{l}\text { Ultimate load } \\
(\mathrm{KN})\end{array}$ & $\begin{array}{l}\text { Deflection } \\
\text { at ult. load } \\
(\mathrm{mm})\end{array}$ & $\begin{array}{l}\text { Ultimate load } \\
(\mathrm{kN})\end{array}$ & $\begin{array}{l}\text { Deflection } \\
\text { at ult. load } \\
(\mathrm{mm})\end{array}$ & & & & \\
\hline $\mathrm{HC} 0.0-0.0$ & 558.32 & 4.06 & 697.72 & 4.89 & 24.97 & 20.44 & 4.72 & 12.52 \\
\hline HC0.7-0.1 & 761.9 & 5.19 & 744.61 & 5.02 & 2.27 & 3.28 & & \\
\hline $\mathrm{HC} 0.7-0.3$ & 751.16 & 5.98 & 746.34 & 5.13 & 0.64 & 14.21 & & \\
\hline HC0.7-0.5 & 768.75 & 6.27 & 741.91 & 5.32 & 3.49 & 15.15 & & \\
\hline $\mathrm{HC} 0.7-0.7$ & 695.69 & 5.45 & 722.31 & 5.88 & 3.83 & 7.89 & & \\
\hline HC0.7-0.9 & 568.5 & 6.74 & 628.7 & 5.65 & 10.59 & 16.17 & & \\
\hline $\mathrm{HC} 0.8-0.1$ & 759.24 & 6.41 & 744.52 & 4.95 & 1.94 & 22.78 & & \\
\hline $\mathrm{HC} 0.8-0.3$ & 800.69 & 8.46 & 782.51 & 7.07 & 2.27 & 16.43 & & \\
\hline HC0.8-0.5 & 821.75 & 7.85 & 729.94 & 6.19 & 11.17 & 21.15 & & \\
\hline HC0.8-0.7 & 698.77 & 6.92 & 727.68 & 5.86 & 4.14 & 15.32 & & \\
\hline $\mathrm{HC} 0.8-0.9$ & 534.23 & 4.96 & 562.43 & 4.95 & 5.28 & 0.20 & & \\
\hline $\mathrm{HC} 0.9-0.1$ & 702.2 & 6.24 & 730.04 & 4.89 & 3.96 & 21.63 & & \\
\hline HC0.9-0.3 & 784.11 & 9.79 & 730.94 & 9.78 & 6.78 & 0.10 & & \\
\hline HC0.9-0.5 & 742.95 & 9.27 & 739.92 & 9.94 & 0.41 & 7.23 & & \\
\hline HC0.9-0.7 & 763.33 & 8.65 & 731.21 & 7.63 & 4.21 & 11.79 & & \\
\hline HC0.9-0.9 & 643.62 & 5.27 & 644.78 & 4.89 & 0.18 & 7.21 & & \\
\hline HC1.0-0.1 & 592.55 & 5.79 & 604.46 & 5.09 & 2.01 & 12.09 & & \\
\hline HC1.0-0.3 & 720.07 & 5.81 & 737.68 & 5.21 & 2.45 & 10.33 & & \\
\hline HC1.0-0.5 & 645.4 & 5.99 & 630.32 & 4.99 & 2.34 & 16.69 & & \\
\hline HC1.0-0.7 & 542.6 & 5.93 & 552.52 & 5.02 & 1.83 & 15.35 & & \\
\hline HC1.0-0.9 & 511.74 & 7 & 534.44 & 7.52 & 4.44 & 7.43 & & \\
\hline
\end{tabular}

This was also observed that in the specimen as the percentage of fibers was increased, the pattern of cracks changed very significantly. For instance, the control specimen had spalled all its covers and cracks appeared very quickly on loading those cracks penetrated deeper on further loading and became a reason for failure. The 
spalled cover showed the tale of failure in samples. And as the minimum percentage of fibers $(0.1 \%$ polypropylene fibers and $0.7 \%$ steel fibers in $\mathrm{HC} 0.7-0.1$ ) were added to the sample, the cracks immediately stopped and were noticeably patterned vertically at the ends and diagonally at the sides.

Thus, providing an optimum percentage of fibers as a combination of polypropylene fibers and steel fibers making a total to $1.0 \%$, as the total percentage increases beyond $1.0 \%$ the material of columns becomes brittle and the width of the crack becomes more prominent after this percentage. After that the cracks start traveling vertically downward at the fiber percentage higher than $1.5 \%$. The reason behind this anomalous behavior of fiber-reinforced concrete is that the fibers start taking load after a certain limit and the stirrups inside the columns expand, pushing the cover of concrete, which is well confined by the fibers. As the push of stirrups and the force because of the bending of steel reinforcement reach the ultimate limit of fibers binding force to that of concrete, they start pushing the concrete cover, hence creating a wider crack.

This can be inferred that up to $1.0 \%$ addition of fibers in short columns make their behavior less brittle and prevents cover spalling in columns up to $100 \%$. Because of the crack arresting nature of fibers added to concrete, a similar trend of the control specimen with abrupt failure and the fibers keeping the cover from spalling was observed [53]. The cracks generally propagated from the point of application of load to inwards, as can be seen in HC0.7-0.3, HCO.70.7, HC0.8-0.1, HC0.8-0.9, HC0.9-0.3, HC0.9-0.7, HC1.0-0.1, $\mathrm{HC} 1.0-0.3, \mathrm{HC} 1.0-0.5$ and $\mathrm{HC} 1.0-0.7$ of Fig. 10 up to the location of one third the height of column specimen. Generally, it was noted down that micro-cracks appeared on all sides of columns depicting that maximum stress concentration was almost negligible, and it was also noted that the width of cracks kept decreasing from end to the center.

The crack patterns in finite element work were represented using the plastic strain (PE) as presented in Fig. 10 which represents that the proposed FEA model traced the experimental crack patterns accurately. The crack patterns are always perpendicular to the direction of the positive principal plastic strain in the concrete damaged plastic model, and thus, they represent the cracking behavior of concrete accurately $[45,51]$. Most of the columns were failed either at the top portion or at the bottom side which accurately predicted by the finite element model.

\subsection{Ultimate loads and corresponding deflections}

The values of the ultimate crushing load for all the column specimens are given in Table 7. The ultimate loadcarrying capacity of the columns has increased from 2.17 to $81.95 \%$; this is also noticeable that the specimens
HC-0.7-0.7, HC0.7-0.9, HC0.8-0.9, HC0.9-0.7, HC0.9-0.9, $\mathrm{HC} 1.0-0.7$, and $\mathrm{HC} 1.0-0.9$ show a minimum increase in the ultimate load-carrying capacity of columns. It is important to note that in all these samples the total percentage of fibers becomes more than $1.5 \%$ by volume of concrete except for HC-0.7-0.7 which has $1.4 \%$. The reason for the unusual performance of this specimen may be associated with the testing of this specimen in the compression testing machine. A minor slippage of the upper load plate was occurred due to the disturbance of the upper surface of the specimen which was unleveled despite providing a layer of plaster with steel collars. This may also be noted that as the polypropylene fibers percentage crosses the threshold of $0.5 \%$ by volume the increase in ultimate loadcarrying capacity starts decreasing, while the maximum values are exhibited on either $0.3 \%$ or $0.5 \%$ polypropylene fibers by volume of concrete. This behavior is because at lower percentages of polypropylene fibers the improvement in ultimate load-carrying capacity is seen because of the crack arresting phenomenon and the load taken by fibers to withstand the cracks and avoid failure. But as the addition of polypropylene fibers is made beyond a certain threshold, the ultimate load-carrying capacity is reduced because a higher volume of polypropylene fibers starts interfering with the cohesion of the concrete matrix.

The ultimate loads of HFRC columns for different quantities of SF and PPF are represented in Fig. 11. The general trend of the curves represents that the axial capacity and axial deflection of columns increase with the percentage content of steel and polypropylene fibers up to a certain quantity, and then both the parameters decrease with a further increase in fibers content. When polypropylene fibers increase from 0 to $0.5 \%$ at $0.7 \%$ steel fibers, the maximum percentage increases in the load and axial deflection were $37.69 \%$ and $54.43 \%$, respectively. Similarly, when the polypropylene fibers increase from 0.1 to $0.9 \%$ at $0.9 \%$ steel fibers, the maximum increase in load and capacity was observed at $0.5 \%$ polypropylene fibers which were $8.23 \%$ and $22.46 \%$, respectively. Similarly, at $0.9 \%$ steel fibers, the maximum load and deflections were observed at $0.3 \%$ polypropylene fibers, and at $1.0 \%$ steel fibers, the maximum load and deflections were observed at $0.3 \%$ and $0.9 \%$ of polypropylene fibers, respectively. The maximum capacity was observed at $0.8 \%$ steel fibers and $0.5 \%$ polypropylene fibers for specimen $\mathrm{HC} 0.8-0.5$ with values of $821 \mathrm{kN}$ and the maximum deflection was observed at $0.9 \%$ steel fibers and $0.3 \%$ polypropylene fibers for specimen HC0.9-0.3 with a value of $9.79 \mathrm{~mm}$. Generally, this study portrayed that the axial capacity of HFRC columns increases with the enhancement in the quantity of hybrid fibers up to a certain content (normally 1.5\%), but further increase in fiber content causes the decrease in the axial strength of specimens. The proposed constitutive FEA 
Fig. 10 Crack patterns of all the HFRC column specimens obtained from experiments and FEA

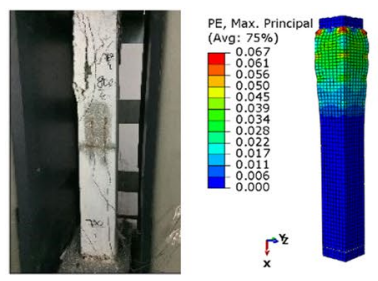

HC $0.0-0.0$

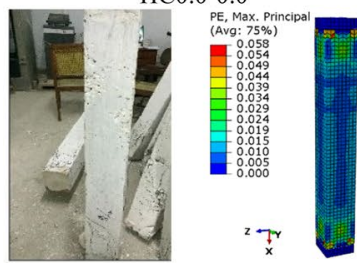

HC0.7-0.5

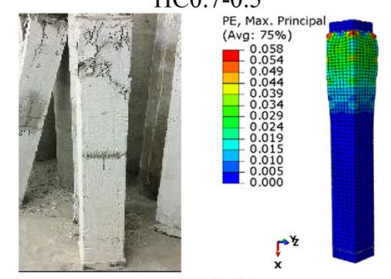

HC $0.8-0.1$

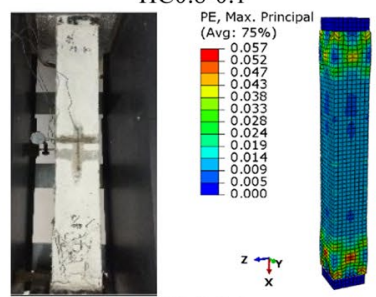

HC0.8-0.7
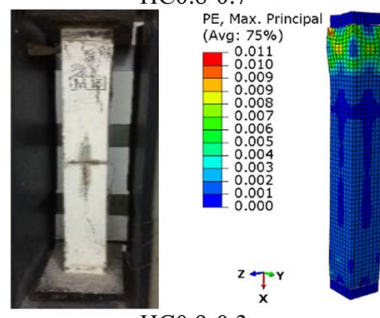

HC0.9-0.3
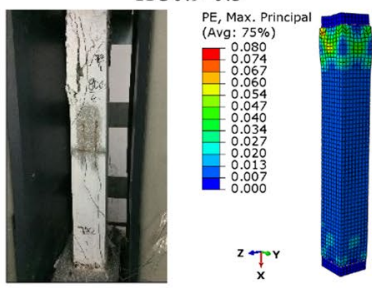

HC0.9-0.9

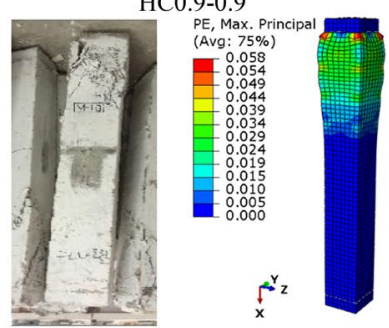

HC1.0-0.5
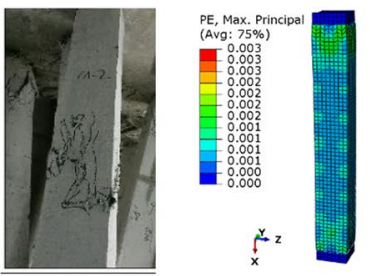

HC 0.7-0.1

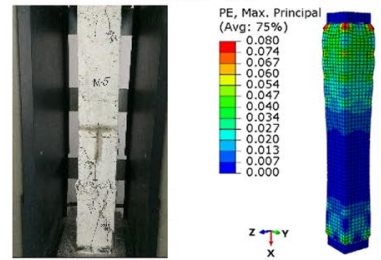

HC 0.7-0.7

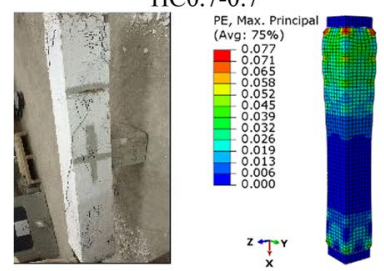

HC 0.8-0.3
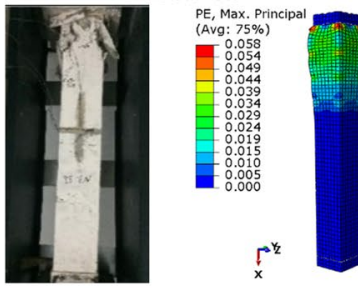

HC0.8-0.9
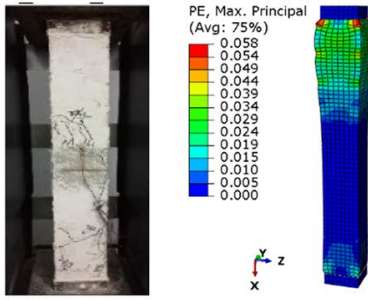

HC0.9-0.5
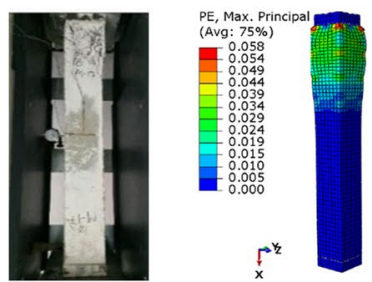

HC1.0-0.1

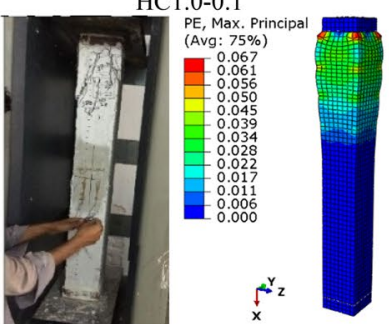

HC 1.0-0.7

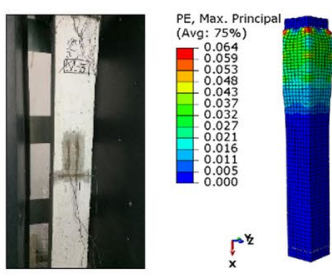

HC0.7-0.3

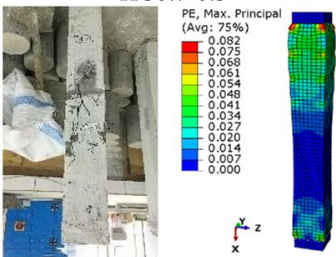

HC0.7-0.9

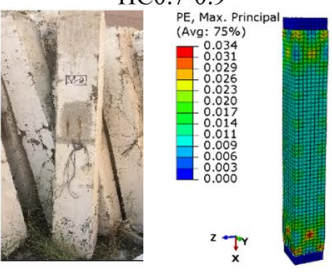

HC0.8-0.5

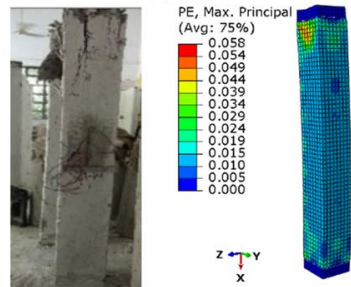
HC0.9-0.1

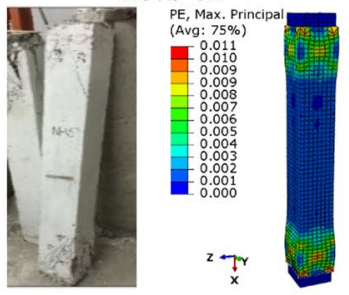

HC0.9-0.7

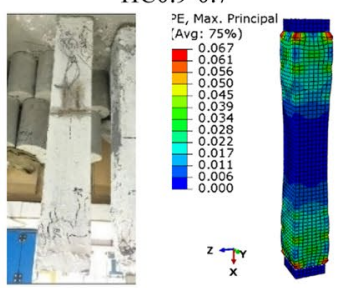

HC1.0-0.3

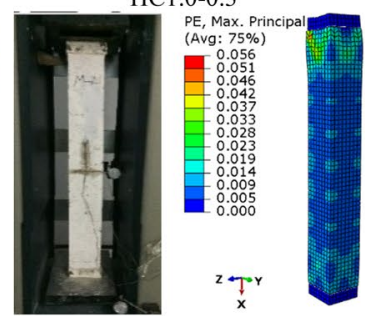

HC1.0-0.9 
Fig. 11 Experimental (EXP) and FEA results for ultimate capacities and corresponding axial deflections of HFRC columns, respectively, for different ratios of SF and PPF
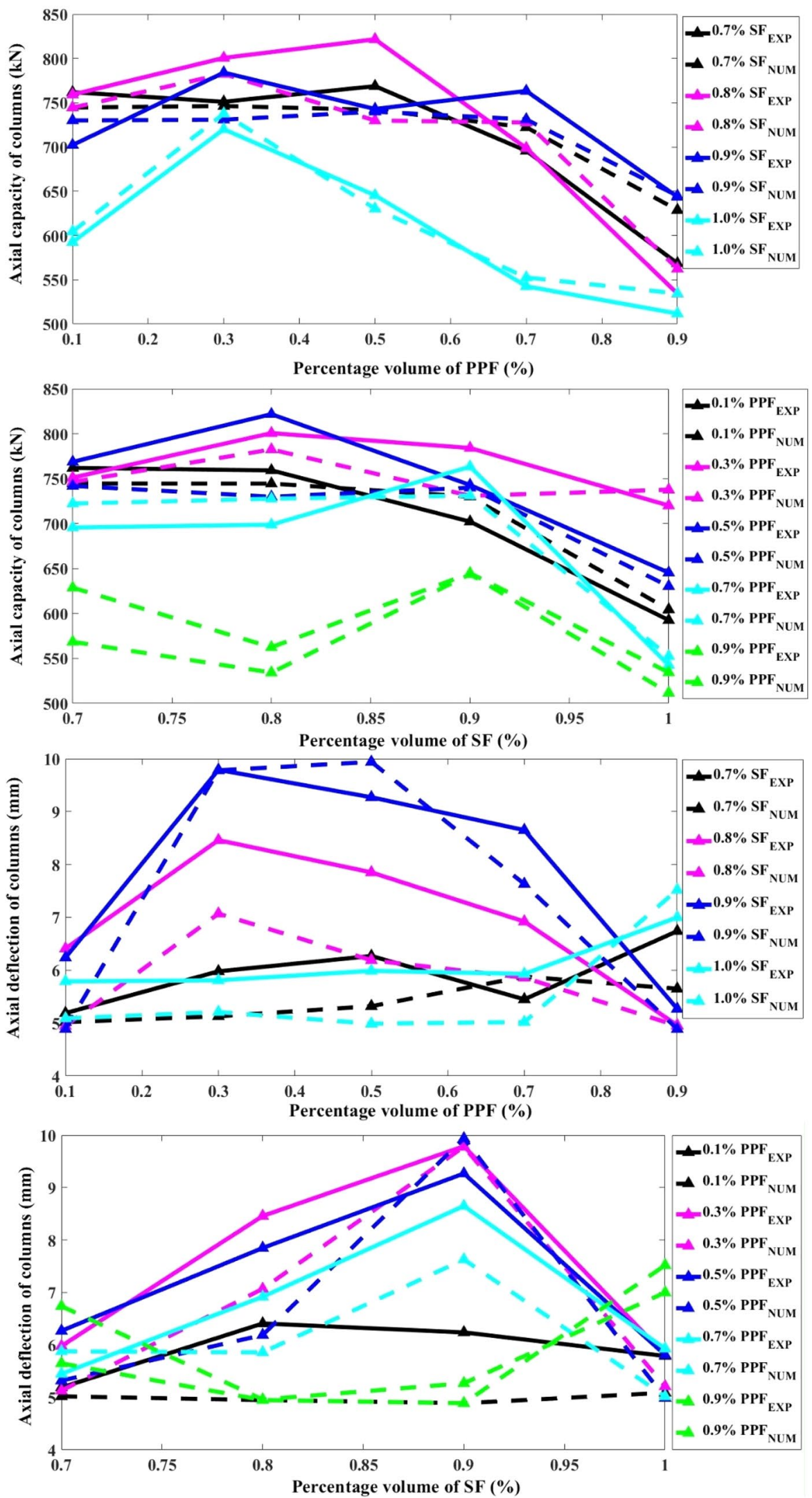
models predicted the ultimate load and corresponding deflections accurately. The trends of fiber-contents against axial loads and axial deflections curves were similarly giving the maximum values at the same quantities of fibers as experimental results.

\subsection{Axial load-axial shortening behavior}

The difference in load first and the final crack load was observed ranging from 2.48 to $180.54 \%$ the first crack load. This percentage difference can be depicted as the ductility induced into the samples with the addition of fibers. This can be noted in Table 7 and Fig. 12 that the specimen containing $0.7 \%$ polypropylene fibers has the least percentage difference of first crack loads. Another trend is noticeable here, that the difference initially decreases up to the addition of $0.7 \%$ polypropylene fibers then once again rises. The decrease in the value is attributed to the relatively brittle nature of randomly distributed fibers. This is because of the crack arresting nature of fibers until their ultimate strain is reached and when the ultimate strain of fibers is reached it fails relieving the cracks which abruptly expand on the failure of fiber elements. Hence, the difference of first visible crack load to the ultimate crack load keep decreasing up to a certain limit. After that limit, the fibers start affecting the bonding of concrete due to which the first crack load is reduced, and the section starts cracking rapidly; hence the difference between first and ultimate crack loads keeps increasing.

It can be observed that the load-deflection response of HFRC columns was predicted by the proposed finite element model with high accuracy. The maximum discrepancy for the ultimate loading capacity was observed for the specimen with plain concrete ( $\mathrm{HCO} .0-0.0)$ with a value of $24.97 \%$, and the minimum discrepancy was observed for $\mathrm{HC} 0.9-0.9$ which was $0.18 \%$. The maximum discrepancy for the axial deflection at the ultimate load was observed for HC0.8-0.1 with a value of $22.78 \%$. Similarly, the minimum percentage discrepancy of $0.1 \%$ was represented by specimen HC-0.9-0.3 for deflection. The average percentage discrepancies between the experimental and FEA results of HFRC columns were $4.72 \%$ and $12.52 \%$ for axial strength and corresponding axial shortening, respectively. These minor discrepancies may be attributed to the following reasons. (1) Minor inaccuracies due to the difference between actual and testing and boundary conditions. (2) Differences in strengths of materials such as concrete and steel reinforcement. (3) Faults in the manufacturing of specimens in the laboratory. (4) Inaccuracies are due to assumptions and conditions made during FEA. (5) Initial geometric imperfections of specimens. (6) Faults in the manufacturing of materials in factory giving different properties of each material such as cement or steel bars. (7) Accuracy of testing instruments. However, the overall experimental load-deflection curves of all the columns were tracked accurately by the FEA results showing that the selected constitutive FEA model can be utilized for the simulations of HFRC compression members.

\subsection{Ductility of HFRC columns}

Figure 13 represents the ductility indices of all the HFRC columns. Ductility is the amount of energy absorbed by the concrete structural element after peak load-carrying capacity. It was observed that the trend of increase or decrease in the ductility of specimens was the same as that of the axial shortening of columns. The ductility index was calculated by using the relationship [54]:

$I_{P}=\frac{\text { Area }_{75 \%}}{\text { Area }_{85 \%}}$

where Area $_{75 \%}$ is the total area of the load-deflection curve up to $75 \%$ of ultimate load-carrying capacity and Area $_{85 \%}$ is the total area of the load-deflection curve of HFRC columns at $85 \%$ of the ultimate load-carrying capacity of columns. However, the ductility index of HFRC columns increased with the increasing volumetric fraction of the hybrid fibers, but it can be observed that with the increase in the quantity of PPF, the ductility index of HFRC columns increases significantly. The ductility of the column with $0.8 \% \mathrm{SF}$ and $0.3 \%$ PPF was similar to that of the plain concrete column. The columns HC0.7-0.3, HCO.8-0.9, HC0.9-0.7 and $\mathrm{HC} 1.0-0.9$ presented the highest ductility indices that were $27.5 \%, 65 \%, 53.34 \%$ and $55.84 \%$ higher than of the plain concrete column. The ductility index was observed to be the highest for the specimens with $0.8 \%$ steel fibers and $0.9 \%$ polypropylene fibers. Therefore, it can be concluded from the current study that the ductility of HFRC columns improves by enhancing the quantity of steel and polypropylene fibers. This improvement is due to the bridging effect of hybrid fibers on the HFRC columns.

\section{Theoretical capacity of hfrc columns}

The experimental and FEA results of axial nominal loadcarrying capacity of HFRC columns were compared with the empirical predictions of various previously proposed capacity equations and international standards for columns with different reinforcement types to investigate which equation gives better results for the nominal capacity of HFRC columns.

Generally, the axial capacity of reinforced concrete columns is equal to the sum of the load-carrying capacities of concrete core and internal reinforcement. According to $\mathrm{ACI}$ 
Fig. 12 Complete axial loaddeflection curves of HFRC columns
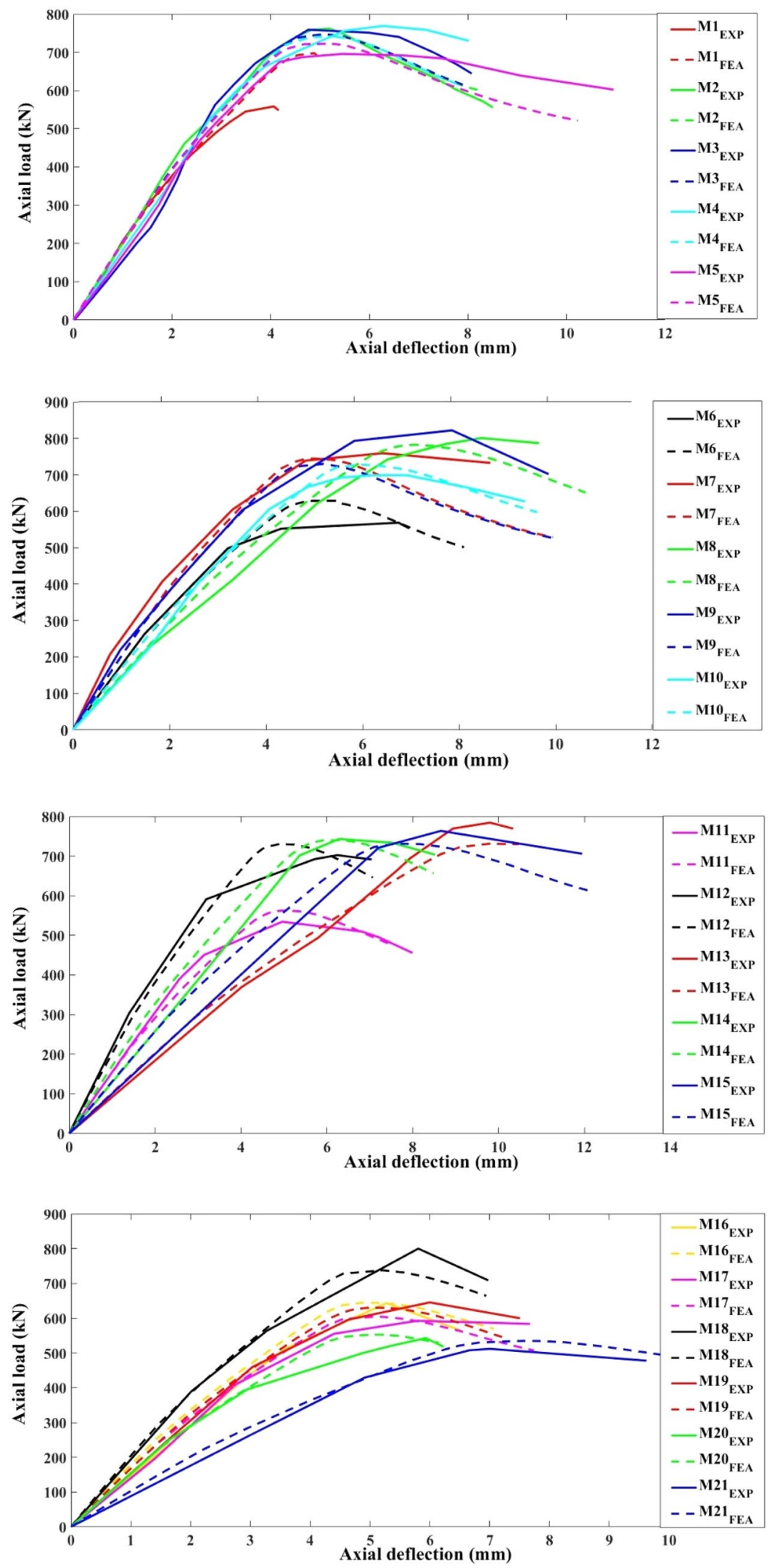


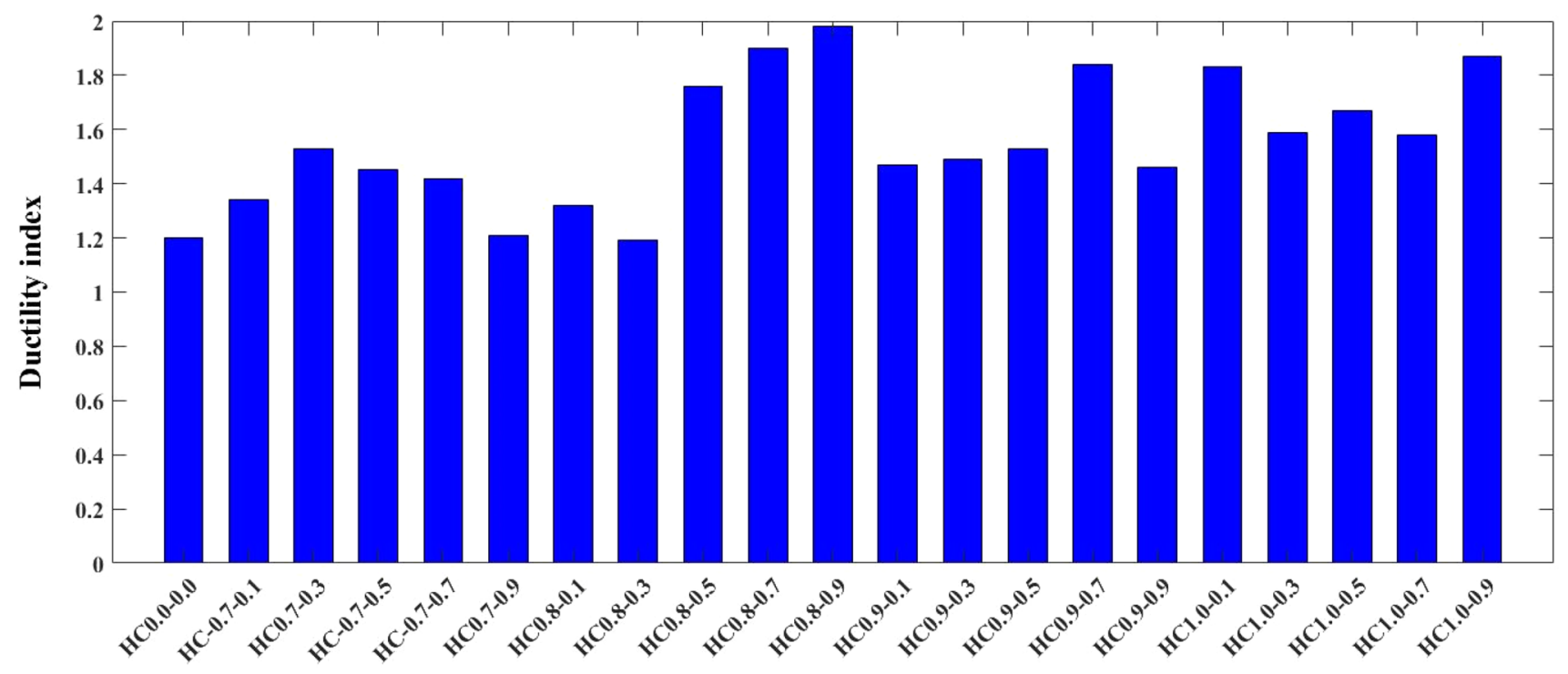

Fig. 13 Ductility indices of various HFRC column specimens

318-11 [55], the axial capacity of short columns can be calculated using Eq. (8).

$P_{0}=0.85 f_{\mathrm{c}}^{\prime}\left(A_{\mathrm{g}}-A_{\mathrm{st}}\right)+A_{\mathrm{st}} f_{\mathrm{y}}$

where $P_{\mathrm{o}}$ is the axial load-carrying capacity of the column, $f_{c}^{\prime}$ is the concrete compressive strength, $A_{\mathrm{g}}$ is the crosssectional area of the concrete region, $A_{\mathrm{st}}$ is the total crosssectional area of internal steel reinforcement, and $f_{\mathrm{y}}$ is the yield strength of reinforcement.

According to British Standard BS 8110 [56], the nominal axial load-carrying capacity of short columns under concentric loading is defined as:

$N=F_{\mathrm{c}}+F_{\mathrm{s}}$

where $N$ is the nominal capacity of steel-RC columns, $F_{c}$ is the portion of the axial strength of columns carried by the concrete core and Fs is the portion of the axial strength of columns due to the longitudinal reinforcement. Thus, Eq. (9) can be written as:

$N=0.45 f_{\mathrm{cu}} A_{\mathrm{c}}+0.87 f_{\mathrm{y}} A_{\mathrm{sc}}$

In this equation, $f_{\mathrm{cu}}$ is the concrete strength, $A_{\mathrm{c}}$ is the cross-sectional area of the concrete core, $f_{\mathrm{y}}$ is the yield strength of reinforcement and $A_{s c}$ is the cross-sectional area of longitudinal reinforcement in the column.

According to Canadian Standard 1984 [57], the axial strength of the column $\left(P_{n}\right)$ is defined as presented in Eq. (11).

$P_{n}=0.51 f_{c}^{\prime} A_{n}+A_{s t} f_{y}$ where $A_{n}$ is the cross-sectional area of concrete. A previously proposed equation for glass fiber-reinforced concrete (GFRP) columns was also evaluated to examine its performance for HFRC columns. Afifi et al. [58] proposed an empirical model for the axial capacity of GFRP-RC columns represented by Eq. (12).

$P_{\mathrm{o}}=0.85 f_{\mathrm{c}}^{\prime}\left(A_{\mathrm{g}}-A_{F}\right)+\alpha_{\mathrm{g}} f_{f u} A_{F}$

where $P_{\mathrm{o}}$ is the axial capacity of GFRP reinforced column, $f_{c}^{\prime}$ is the concrete strength, $A_{g}$ is the gross cross-sectional area of concrete, $A_{F}$ is the cross-sectional area of main FRP/ steel reinforcement, $\alpha_{g}$ is the reduction factor. The value of this factor can be taken as $0.35[59,60]$.

The performance of all the above-mentioned codes and equations for various reinforcement types in RC columns is presented in Fig. 14. The predictions of $\mathrm{ACl}$ code [55] overestimated the axial capacities of HFRC columns showing that this equation cannot be used for the calculation of load-carrying capacity of HFRC columns. Furthermore, British Standard [56] and Canadian Standard [57] underestimated the axial capacity of HFRC columns.

As concerned with the equation given by Afifi et al. [58], the predictions were close to experimental measurements. Although this equation was proposed for the axial load-carrying capacity of the GFRP-RC columns, its predictions gave a better performance for the capacity of HFRC columns as compared with other equations given by $\mathrm{ACl}$ 318-11 [55], British Standard BS 8110 [56] and Canadian Standard 1984 [57]. The average percentage discrepancies for ACI 318-11 [55], British Standard BS 8110 [56], Canadian Standard 1984 [57] and Afifi et al. [58] were 23.64\%, 


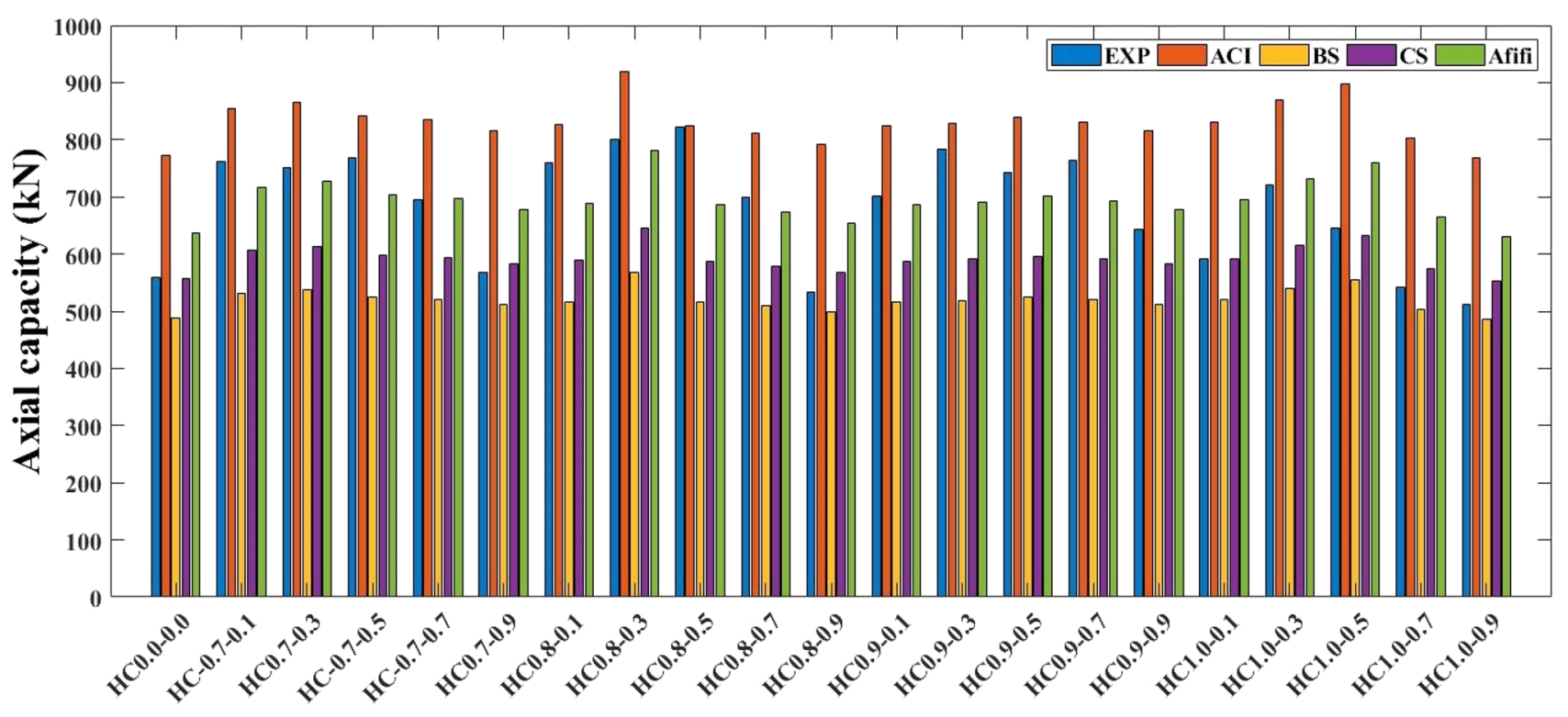

Fig. 14 Experimental results and predictions of various codes and equations for the axial capacity of HFRC columns

$22.66 \%, 14.06 \%$ and $10.55 \%$, respectively. Thus, the equation of GFRP-RC columns given by Afifi et al. [58] can predict the axial behavior of HFRC columns with comparatively higher accuracy. Moreover, a constitutive empirical model should be proposed for predicting the behavior of HFRC columns with high accuracy.

Figure 15 represents the ratios of experimental to predicted values of the axial load-carrying capacity of HFRC columns. The ratios of experimental to predicted values by $\mathrm{ACl}$ Code are smaller than all other codes and equations due to the overestimation of the $\mathrm{ACl}$ Code for the axial capacity of HFRC columns. ACl Code gave the accurate prediction for the column specimen with $0.8 \%$ steel fibers and $0.5 \%$ polypropylene fibers ( $\mathrm{HC} 0.8-0.5)$, but most of the ratios were smaller than unity. The ratios of experimental to predicted values by British Standard were larger than all

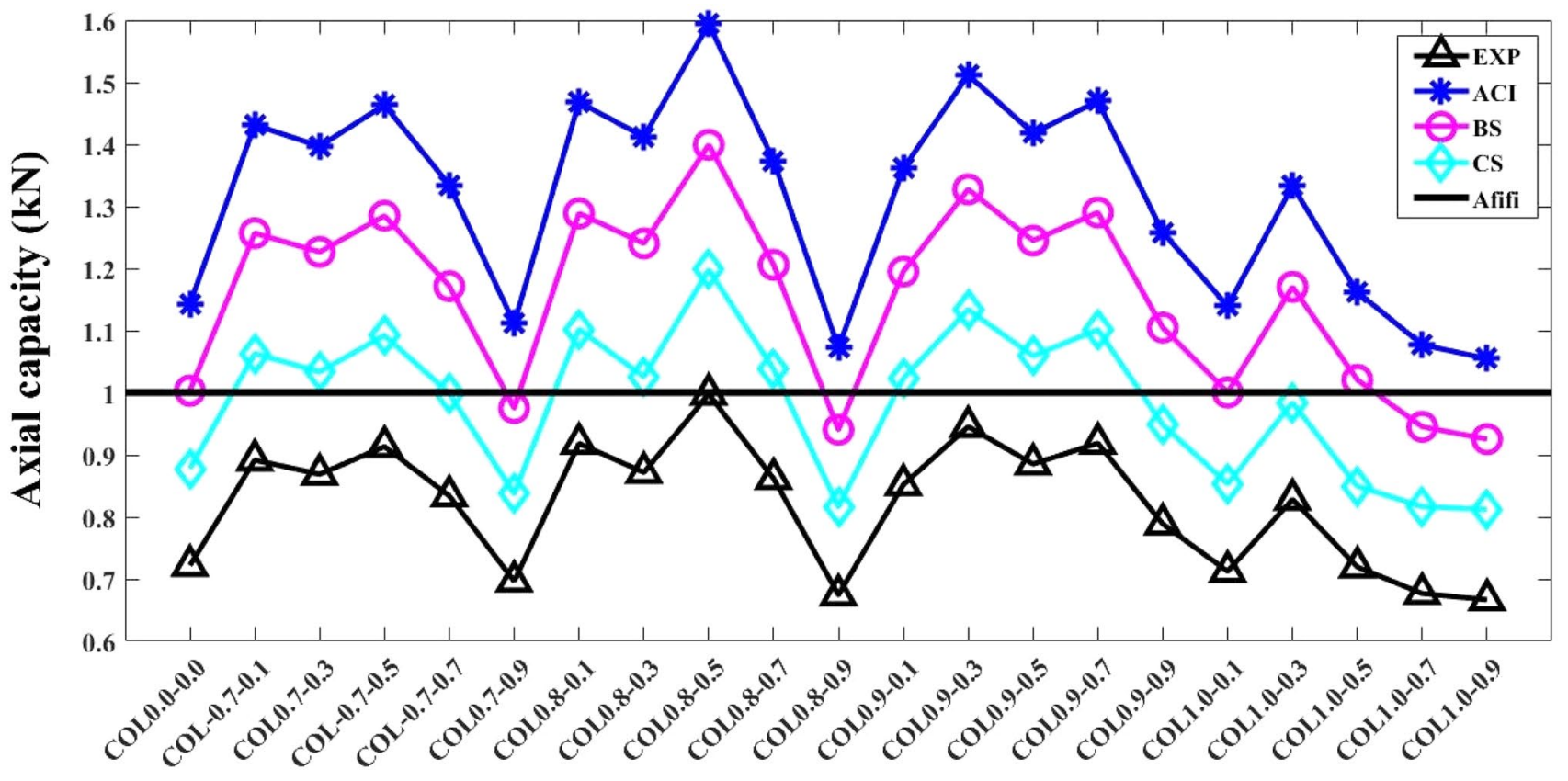

Fig. 15 Ratios of experimental to predicted values of the axial capacity of HFRC columns 
other codes and equations due to the underestimation of this code for the axial capacity of HFRC columns. The equation proposed by Afifi et al. [58] gave ratios that were very close to the unity showing that this equation predicts the axial load-carrying capacity of HFRC columns accurately.

\section{Conclusions}

The main conclusions drawn from the present research work are as under:

The maximum load-carrying capacity of HFRC columns was achieved at a combination of $0.8 \%$ steel fibers and $0.5 \%$ polypropylene fibers by the total volume of the specimen. Similarly, the maximum deflection at the ultimate load was achieved while using $0.9 \%$ steel fibers and $0.3 \%$ polypropylene fibers. The proposed FE model gave the maximum load-carrying capacity at a combination of $0.8 \%$ steel fibers and $0.3 \%$ polypropylene fibers, and the maximum deflection was achieved at a combination of $0.9 \%$ steel fibers and $0.5 \%$ polypropylene fibers. It was observed that the axial loading capacity of HFRC columns increased with the increase in hybrid fibers upto a certain content ( $1.5 \%$ by volume), and then, it started to decrease with the increase in fiber quantity. Furthermore, the ductility of the specimens was seemed to be increased with the quantity of fibers (up to $1.9 \%$ ).

This can be observed that up to $1.0 \%$ addition of fibers in columns makes their behavior less brittle and prevents cover spalling in columns up to $100 \%$. When the total percentage increases beyond $1.0 \%$, the material of columns becomes brittle and the width of the crack becomes more prominent after this percentage. The proposed FE model predicted the crack patterns of HFRC columns with accuracy.

The ductility index of HFRC columns was observed to be the highest for the specimens with $0.8 \%$ steel fibers. The ductility was maximum for the specimen with $0.8 \%$ steel fibers and $0.9 \%$ polypropylene fibers.

The proposed FE model captured the load-deflection behavior of HFRC columns accurately. The average percentage discrepancies between the experimental measurements and FE predictions for the axial loading capacity and corresponding deflection were $4.72 \%$ and $12.52 \%$, respectively. These minor discrepancies represent that the proposed FE model is accurate enough to closely predict the axial behavior of HFRC compression members.

The extensive study of various international standards for predicting the axial load-carrying capacity of columns represents that the proposed equation by $\mathrm{ACl}$ Code for steel-reinforced columns cannot accurately predict but overestimates the results for the axial loading capacity of HFRC columns by $23.64 \%$. Conversely, the British Standard and Canadian Standard underestimate the axial capacity of HFRC columns by $22.66 \%$ and $14.06 \%$, respectively. The equation proposed for GFRP-RC columns by Afifi et al. (2013) gave the close approximations for the axial capacities of HFRC columns with $10.55 \%$. Thus, this equation can be used for approximately predicting the axial capacity of HFRC short columns. Furthermore, there is a need to propose an empirical model that can predict the axial behavior of HFRC columns with higher accuracy.

Acknowledgements The authors acknowledge the support for testing the specimens in Concrete Structural Laboratory of Civil Engineering Department of the University of Engineering and Technology, Taxila.

Author's contribution Both authors contributed to the present research work. The first author (corresponding author) worked with respect to the experimental testing and finite element modeling of HFRC specimens and wrote the manuscript. The second author gave research conception, complied and reviewed the manuscript for comments.

Data availability Data including ABAQUS codes and experimental results are available on request from the corresponding author.

\section{Compliance with ethical standard}

Conflict of interest The authors declare that they have no conflict of interests.

\section{References}

1. Gu DS, Wu YF, Wu G, Wu ZS (2012) Plastic hinge analysis of FRP confined circular concrete columns. Constr Build Mater 27(1):223-233. https://doi.org/10.1016/j.conbuildma t.2011.07.056

2. Zsarnóczay Á, Vigh LG, Kollár LP (2013) Seismic performance of conventional girder bridges in moderate seismic regions. J Bridge Eng 19(5):04014001. https://doi.org/10.1061/(asce) be.1943-5592.0000536

3. Bayramov F, Taşdemir C, Taşdemir MA (2004) Optimisation of steel fibre reinforced concretes by means of statistical response surface method. Cement Concr Compos 26(6):665-675. https:// doi.org/10.1016/s0958-9465(03)00161-6

4. Pang Y, Cai L, Ouyang H, Zhou X (2019) Seismic performance assessment of different fibers reinforced concrete columns using incremental dynamic analysis. Constr Build Mater 203:241-257. https://doi.org/10.1016/j.conbuildmat.2019.01.087

5. Darole JS, Kulkarni VP, Shaikh AP, Gite BE (2013) Effect of hybrid fibre on mechanical properties of concrete. Int J Eng Res Appl 3:1408

6. Afroughsabet V, Geng G, Lin A, Biolzi L, Ostertag CP, Monteiro PJ (2019) The influence of expansive cement on the mechanical, physical, and microstructural properties of hybrid-fiberreinforced concrete. Cement Concr Compos 96:21-32. https:// doi.org/10.1016/j.cemconcomp.2018.11.012

7. Vairagade VS, Kene KS (2013) Strength of normal concrete using metallic and synthetic fibers. Procedia Eng 51:132-140. https:// doi.org/10.1016/j.proeng.2013.01.020 
8. JR Deluce, FJ Vecchio (2011) Cracking behavior of steel fiberreinforced concrete members containing conventional reinforcement. ACI Struct J. https://doi.org/10.14359/51685605

9. Tiberti G, Minelli F, Plizzari G (2015) Cracking behavior in reinforced concrete members with steel fibers: a comprehensive experimental study. Cem Concr Res 68:24-34. https://doi. org/10.1016/j.cemconres.2014.10.011

10. Yang JM, Kim JK, Yoo DY (2016) Effects of amorphous metallic fibers on the properties of asphalt concrete. Constr Build Mater 128:176-184. https://doi.org/10.1016/j.conbuildma t.2016.10.082

11. Yew MK, Othman I, Yew MC, Yeo SH, Mahmud HB (2011) Strength properties of hybrid nylon-steel and polypropylene-steel fibre-reinforced high strength concrete at low volume fraction. Int Phys Sci 6(33):7584-7588. https://doi. org/10.5897/ijps11.736

12. Ali B, Qureshi LA, Raza A, Nawaz MA, Safi UR, Rashid MU (2019) Influence of glass fibers on mechanical properties of concrete with recycled coarse aggregates. Civil Engineering Journal 5(5):1007-1019. https://doi.org/10.28991/cej-2019-03091307

13. Caggiano A, Folino P, Lima C, Martinelli E, Pepe M (2017) On the mechanical response of hybrid fiber reinforced concrete with recycled and industrial steel fibers. Constr Build Mater 30(147):286-295. https://doi.org/10.1016/j.conbuildma t.2017.04.160

14. Avanaki M, Abedi M, Hoseini A, Maerefat MS (2018) Effects of fiber volume fraction and aspect ratio on mechanical properties of hybrid steel fiber reinforced concrete. J New Approaches Civil Eng 2(2):49-64. https://doi.org/10.30469/JNACE.2018.69394

15. Tioua T, Kriker A, Barluenga G, Palomar I (2017) Influence of date palm fiber and shrinkage reducing admixture on self-compacting concrete performance at early age in hot-dry environment. Constr Build Mater 154:721-733. https://doi.org/10.1016/j. conbuildmat.2017.07.229

16. Fallah S, Nematzadeh M (2017) Mechanical properties and durability of high-strength concrete containing macro-polymeric and polypropylene fibers with nano-silica and silica fume. Constr Build Mater 132:170-187. https://doi.org/10.1016/j.conbu ildmat.2016.11.100

17. Macanovskis A, Krasnikovs A, Kononova O, Lukasenoks A (2017) Mechanical behavior of polymeric synthetic fiber in the concrete. Procedia Eng 172:673-680. https://doi.org/10.1016/j. proeng.2017.02.079

18. Ozawa M, Sakoi Y, Fujimoto K, Tetsura K, Parajuli SS (2017) Estimation of chloride diffusion coefficients of high-strength concrete with synthetic fibres after fire exposure. Constr Build Mater 143:322-329. https://doi.org/10.1016/j.conbuildma t.2017.03.117

19. Banthia N, Gupta R (2004) Hybrid fiber reinforced concrete (HyFRC): fiber synergy in high strength matrices. Mater Struct 37(10):707-716. https://doi.org/10.1617/14095

20. Wu Z, Shi C, He W, Wang D (2017) Static and dynamic compressive properties of ultra-high performance concrete (UHPC) with hybrid steel fiber reinforcements. Cement Concr Compos 79:148-157. https://doi.org/10.1016/j.cemconcomp .2017 .02 .010

21. Lu Y, Liu Z, Li S, Hu J (2018) Axial compression behavior of hybrid fiber reinforced concrete filled steel tube stub column. Constr Build Mater 174:96-107. https://doi.org/10.1016/j.conbuildma t.2018.04.089

22. Pourfalah S, Suryanto B, Cotsovos DM (2018) Enhancing the out-of-plane performance of masonry walls using engineered cementitious composite. Compos B Eng 140:108-122. https:// doi.org/10.1016/j.compositesb.2017.12.030

23. Padanattil A, Karingamanna J, Mini KM (2017) Novel hybrid composites based on glass and sisal fiber for retrofitting of reinforced concrete structures. Constr Build Mater 133:146-153. https://doi.org/10.1016/j.conbuildmat.2016.12.045

24. Pourfalah S, Cotsovos DM, Suryanto B (2018) Modelling the outof-plane behaviour of masonry walls retrofitted with engineered cementitious composites. Comput Struct 201:58-79. https://doi. org/10.1016/j.compstruc.2018.02.004

25. Yazıcı Ş, İnan G, Tabak V (2007) Effect of aspect ratio and volume fraction of steel fiber on the mechanical properties of SFRC. Constr Build Mater 21(6):1250-1253. https://doi.org/10.1016/j. conbuildmat.2006.05.025

26. Köksal F, Altun F, Yiğit I, Şahin Y (2008) Combined effect of silica fume and steel fiber on the mechanical properties of high strength concretes. Constr Build Mater 22(8):1874-1880. https ://doi.org/10.1016/j.conbuildmat.2007.04.017

27. Li B, Chi Y, Xu L, Shi Y, Li C (2018) Experimental investigation on the flexural behavior of steel-polypropylene hybrid fiber reinforced concrete. Constr Build Mater 191:80-94. https://doi. org/10.1016/j.conbuildmat.2018.09.202

28. Pakravan HR, Latifi M, Jamshidi M (2017) Hybrid short fiber reinforcement system in concrete: a review. Constr Build Mater 142:280-294. https://doi.org/10.1016/j.conbuildma t.2017.03.059

29. Zhang C, Han S, Hua Y (2018) Flexural performance of reinforced self-consolidating concrete beams containing hybrid fibers. Constr Build Mater 174:11-23. https://doi.org/10.1016/j.conbu ildmat.2018.04.075

30. Suksawang N, Wtaife S, Alsabbagh A (2018) Evaluation of elastic modulus of fiber-reinforced concrete. ACI Mater J. https://doi. org/10.14359/51701920

31. Ayub T, Shafiq N, Khan SU (2015) Compressive stress-strain behavior of HSFRC reinforced with basalt fibers. J Mater Civ Eng 28(4):06015014. https://doi.org/10.1061/(asce)mt.19435533.0001441

32. Maruthachalam D, Padmanaban I, Vishnuram BG (2013) Influence of polyolefin macro-monofilament fibre on mechanical properties of high performance concrete. KSCE J Civil Eng 17(7):1682-1689. https://doi.org/10.1007/s12205-013-0399-5

33. Khan QZ, Ahmad A, Tahir F, Mehboob S, Raza A (2019) Proposed Equation of elastic modulus of hybrid fibers reinforced concrete cylinders. Technical Journal 24(01):9-20

34. Shi Y, Swait T, Soutis C (2012) Modelling damage evolution in composite laminates subjected to low velocity impact. Compos Struct 94(9):2902-2913. https://doi.org/10.1016/j.compstruct .2012.03.039

35. Matthews FL, Davies GA, Hitchings D, Soutis C (2000) Finite element modelling of composite materials and structures. Elsevier, Amsterdam

36. Chowdhury M, Islam M, Ibna Zahid Z (2016) Finite element modeling of compressive and splitting tensile behavior of plain concrete and steel fiber reinforced concrete cylinder specimens. Adv Civil Eng. https://doi.org/10.1155/2016/6579434

37. ASTM-C150/C150M-18, Standard Specification for Portland Cement, ASTM International, West Conshohocken, PA. 2018.

38. ASTMC33/C33M-18, Standard Specification for Concrete Aggregates, ASTM International, West Conshohocken, PA. 2018.

39. Ouchi M, Hibino M, Okamura H (1997) Effect of superplasticizer on self-compactability of fresh concrete. Transp Res Rec 1574(1):37-40. https://doi.org/10.3141/1574-05

40. ASTMC-494/C494M-17 (2017) Standard Specification for Chemical Admixtures for Concrete, ASTM International, West Conshohocken, $\mathrm{P}$

41. ACl-Committee (2008) Building code requirements for structural concrete ( $\mathrm{ACl}$ 318-08) and commentary. International Organization for Standardization. American Concrete Institute

42. Raza A, Shah SAR, Khan AR, Aslam MA, Khan TA, Arshad K, Hussan S, Sultan A, Shahzadi G, Waseem M (2020) Sustainable 
FRP-confined symmetric concrete structures: an application experimental and numerical validation process for reference data. Appl Sci 10(1):333. https://doi.org/10.3390/app10010333

43. Alfarah B, López-Almansa F, Oller S (2017) New methodology for calculating damage variables evolution in Plastic Damage Model for RC structures. Eng Struct 132:70-86. https://doi. org/10.1016/j.engstruct.2016.11.022

44. Youssf O, ElGawady MA, Mills JE, Ma X (2014) Finite element modelling and dilation of FRP-confined concrete columns. Eng Struct 79:70-85. https://doi.org/10.1016/j.engst ruct.2014.07.045

45. Raza A, Khan QUZ, Ahmad A (2019) Numerical investigation of load-carrying capacity of GFRP-reinforced rectangular concrete members using CDP model in ABAQUS. Adv Civil Eng. https:// doi.org/10.1155/2019/1745341

46. Liu W, Chen Z (2014) Parameters calibration and verification of concrete damage plasticity model of Abaqus. Ind Constr $44: 167-213$

47. De Normalisation CE (2004) Eurocode 2-design of concrete structures-part 1-1: general rules and rules for buildings. Belgium, Brussels

48. Desayi P, Krishnan S (1964) Equation for the stress-strain curve of concrete. J Proc 61(3):345-350

49. Majewski $S$ (2003) The mechanics of structural concrete in terms of elasto-plasticity. Publishing House of Silesian University of Technology, Gliwice

50. Wahalathantri BL, Thambiratnam DP, Chan THT, Fawzia S (2011) A material model for flexural crack simulation in reinforced concrete elements using ABAQUS. In: Proceedings of the first international conference on engineering, designing and developing the built environment for sustainable wellbeing. Queensland University of Technology.

51. Genikomsou AS, Polak MA (2015) Finite element analysis of punching shear of concrete slabs using damaged plasticity model in ABAQUS. Eng Struct 98:38-48. https://doi. org/10.1016/j.engstruct.2015.04.016

52. Kachlakev DI, Miller TH, Potisuk T, Yim SC, Chansawat K (2001) Finite element modeling of reinforced concrete structures strengthened with FRP laminates. Oregon. Dept. of Transportation Research Group, Salem

53. Ikponmwosa EE, Salau MA (2011) Effect of short steel fibre reinforcement on laterized concrete columns. J Sustain Dev 4(1):230. https://doi.org/10.5539/jsd.v4n1p230

54. Elchalakani M, Ma G (2017) Tests of glass fibre reinforced polymer rectangular concrete columns subjected to concentric and eccentric axial loading. Eng Struct 151:93-104. https://doi. org/10.1016/j.engstruct.2017.08.023

55. American Concrete Institute (ACI) (2011) (ACI) Building code requirements for structural concrete $(\mathrm{ACl} 318-11)$ and commentary. ACl 318R-11, Farmington Hills, MI

56. British Standards Institution (1997) 8110 Part 2. Code of Practice for Design and Construction. London

57. Canadian Standards Association (1984) Design of Concrete Structures for Buildings CAN.3-A23.3-M84, National Standard of Canada, Rexdale, Canada

58. Afifi MZ, Mohamed HM, Benmokrane B (2013) Axial capacity of circular concrete columns reinforced with GFRP bars and spirals. J Compos Constr 18(1):04013017. https://doi.org/10.1061/(asce) cc.1943-5614.0000438

59. Kobayashi K, Fujisaki T (1995) 32 compressive behavior of FRP reinforcement in non-prestressed concrete members. InNonMetallic (FRP) Reinforcement for Concrete Structures: Proceedings of the Second International RILEM Symposium, Vol. 29, p. 267, CRC Press.

60. Tobbi H, Farghaly AS, Benmokrane B (2012) Concrete columns reinforced longitudinally and transversally with glass fiberreinforced polymer bars. ACI Struct J 109(4):1. https://doi. org/10.14359/51683874

Publisher's Note Springer Nature remains neutral with regard to jurisdictional claims in published maps and institutional affiliations. 